\title{
Health Literacy and Self-efficacy as correlates of Self- Management of Type 2 Diabetes in Middle-Aged and Older Adults
}

Tomorrow D. Wilson

West Virginia University

Follow this and additional works at: https://researchrepository.wvu.edu/etd

\section{Recommended Citation}

Wilson, Tomorrow D., "Health Literacy and Self-efficacy as correlates of Self-Management of Type 2 Diabetes in Middle-Aged and Older Adults" (2012). Graduate Theses, Dissertations, and Problem Reports. 4938.

https://researchrepository.wvu.edu/etd/4938

This Thesis is protected by copyright and/or related rights. It has been brought to you by the The Research Repository @ WVU with permission from the rights-holder(s). You are free to use this Thesis in any way that is permitted by the copyright and related rights legislation that applies to your use. For other uses you must obtain permission from the rights-holder(s) directly, unless additional rights are indicated by a Creative Commons license in the record and/ or on the work itself. This Thesis has been accepted for inclusion in WVU Graduate Theses, Dissertations, and Problem Reports collection by an authorized administrator of The Research Repository @ WVU. For more information, please contact researchrepository@mail.wvu.edu. 
Health Literacy and Self-efficacy as correlates of Self-Management of Type 2 Diabetes in Middle-Aged and Older Adults

\title{
Tomorrow D. Wilson, B.A.
}

Thesis submitted to the Eberly College of Arts and Sciences

at West Virginia University in partial fulfillment of the requirements

for the degree of

\author{
Master of Science \\ in \\ Psychology
}

\author{
Approved by \\ Julie Hicks Patrick, Ph.D., Committee Chair \\ Christina Duncan, Ph.D. \\ JoNell Strough, Ph.D. \\ Department of Psychology
}
Morgantown, West Virginia 2012

Keywords: diabetes, health literacy, self-efficacy, distress, affect, self-management 


\begin{abstract}
Health Literacy and Self-efficacy as correlates of Self-Management of Type 2 Diabetes in Middle-Aged and Older Adults
\end{abstract}

Tomorrow D. Wilson

The prevalence of type 2 diabetes is increasing with middle-aged and older adults being those at highest risk for developing this disease. Additionally, the demands of type 2 diabetes selfmanagement can become difficult with age, which can result in poorer glycemic control. The current study examined the relations of health literacy, diabetes-related distress, and diabetes self-efficacy on diabetes self-management among 65 adults aged 40-66 with type 2 diabetes. Age was found to be positively associated with health literacy, but negatively associated with diabetes self-care activities. Additionally, only diabetes self-efficacy was found to be a unique contributor to diabetes self-care activities when controlling for age and gender. Lastly, body mass index was found to be negatively associated with diabetes self-efficacy and diabetes self-care activities. Future studies should consider using a longitudinal design to better inform interventions for those at risk for inadequate glycemic control (i.e., overweight/obese individuals, older adults, those with low self-efficacy). 


\section{Acknowledgements}

I would like to thank Dr. Julie Hicks Patrick, my thesis chair and academic advisor, for her support and guidance throughout this project. I also appreciate the comments and suggestions of my other committee members, Dr. JoNell Strough and Dr. Christina Duncan. I also would like to thank my grandmother for her constant support and encouragement through my education and professional development. 


\section{Table of Contents}

1. Problem Statement .....................................................................................................

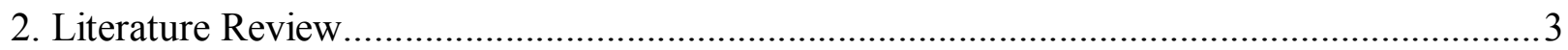

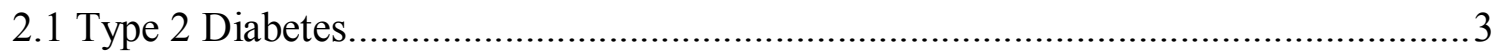

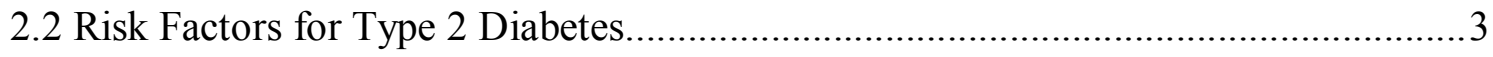

2.3 Self-Managing Type 2 Diabetes..................................................................... 4

2.4 Psychosocial Predictors of Self-Management in Type 2 Diabetes.............................5

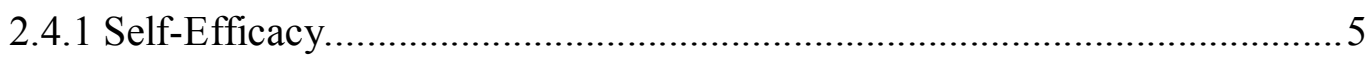

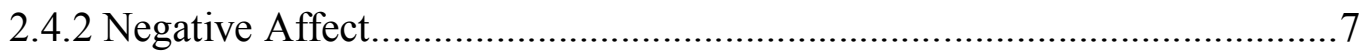

2.5 Health Literacy...................................................... 10

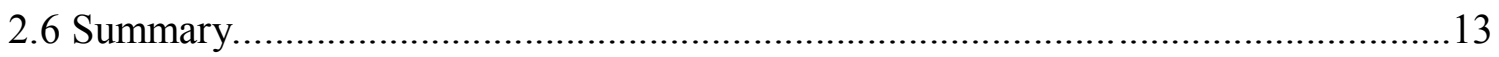

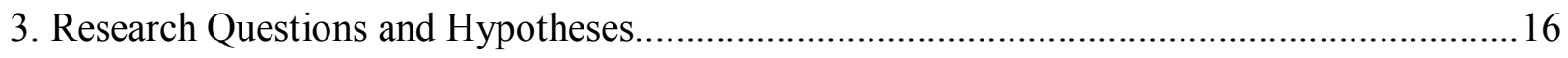

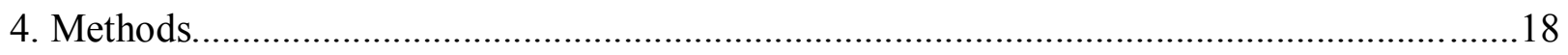

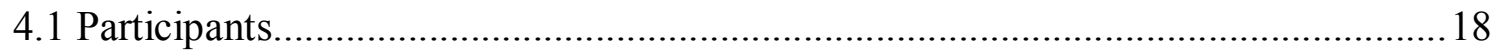

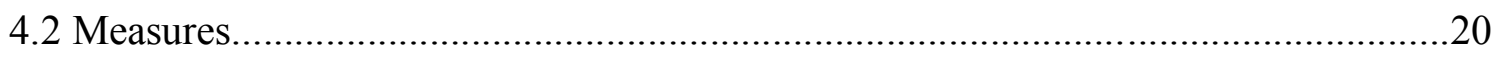

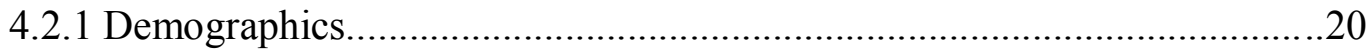

4.2.2 Diabetes Self-Management............................................................20

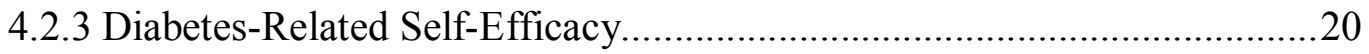

4.2.4 Diabetes-Related Distress...........................................................21

4.2.5 Health Literacy.............................................................................21

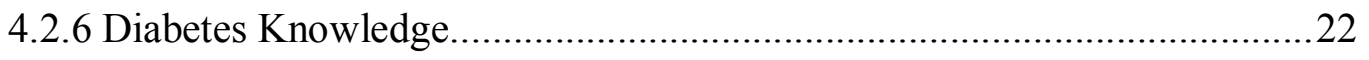

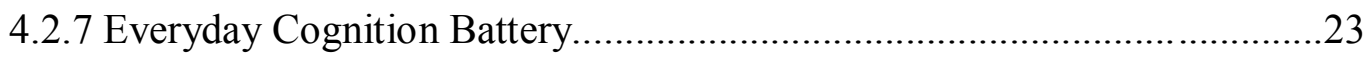

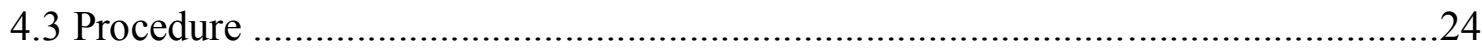

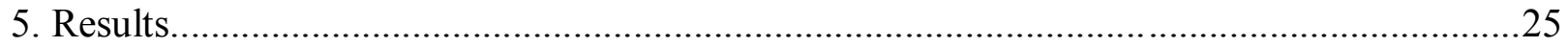

5.1 Preliminary Analyses....................................................... 


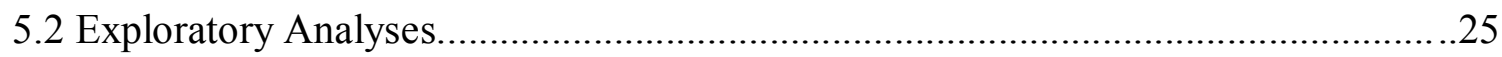

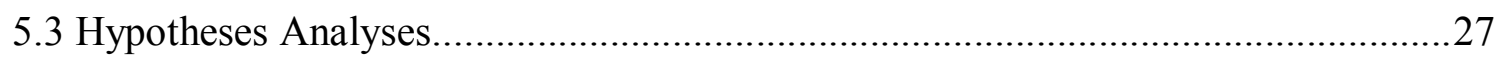

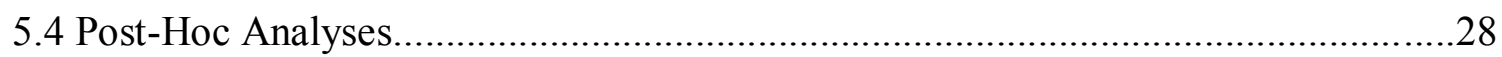

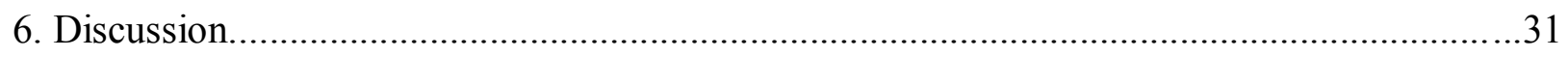

6.1 Age and Health Literacy.........................................................................................31

6.2 Diabetes-Related Self-Efficacy and Diabetes Self-Management................................31

6.3 Diabetes-Related Emotional Distress and Diabetes Self-Management.......................32

6.4 Health Literacy and Diabetes Self-Management.......................................................32

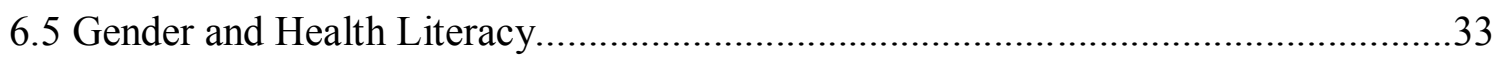

6.6 Length of Diagnosis and Diabetes Self-Management................................................33

6.7 Relation between the Newest Vital Sign, Everyday Cognitive Battery, and Diabetes

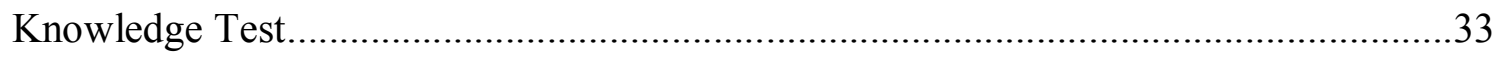

6.8 Other Factors Related to Diabetes Self-Management.................................................34

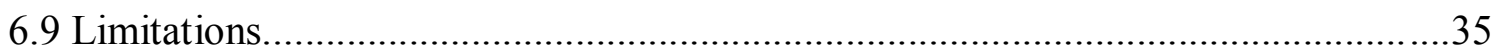

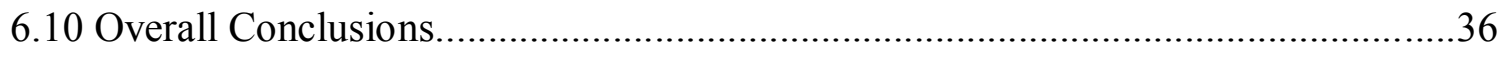

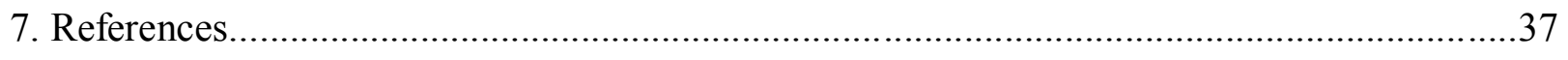

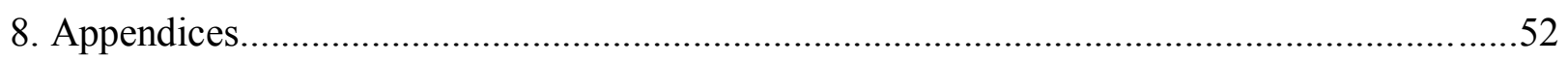

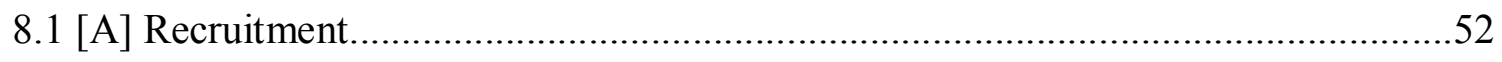

8.2 [B] Summary of Diabetes Self-Care Activities...........................................................53

8.3 [C] Diabetes Empowerment Scale- Short Form......................................................55

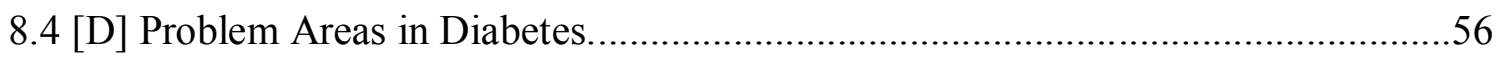

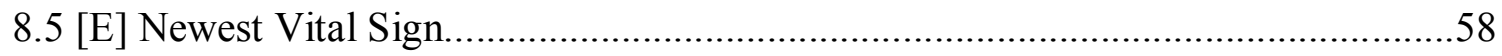

8.6 [F] Diabetes Knowledge Test................................................................................59

8.7 [G] Everyday Cognition Battery: Reasoning Questionnaire.......................................61

$8.8[\mathrm{H}]$ Everyday Cognition Battery: Knowledge Questionnaire.....................................69 


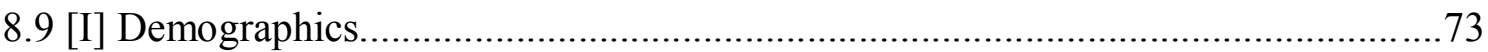




\section{List of Tables}

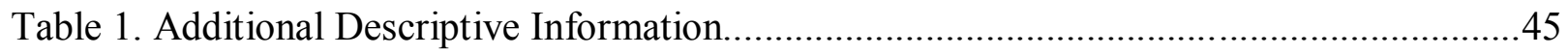

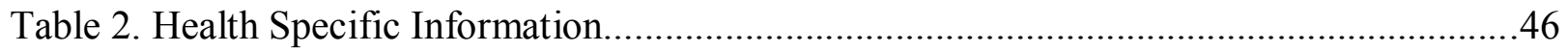

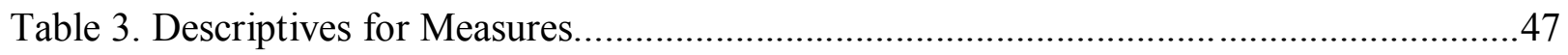

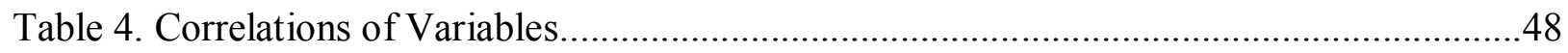

Table 5. Hierarchical Multiple Regression: Diabetes Self-Management regressed onto Distress,

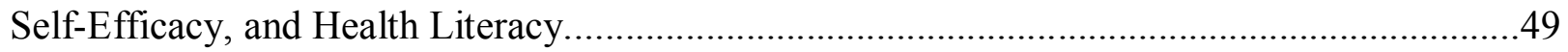


List of Figures

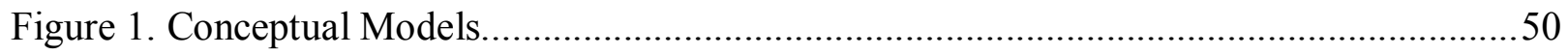

Figure 2. Mediation Model of BMI, Diabetes-Related Self-Efficacy, and Self-Management.....51 
HEALTH LITERACY 1

Health Literacy and Self-efficacy as correlates of Self-Management of Type 2 Diabetes in Middle-Aged and Older Adults

\section{Problem Statement}

Type 2 diabetes (T2D) is a chronic health condition affecting 13.7\% of adults aged 45-64 years and $26.9 \%$ of adults aged 65 years and older. Members of some racial and ethnic minority groups and those who are overweight are at a higher risk of T2D (Center for Disease Control and Prevention [CDC], 2011). If poorly managed, T2D contributes to increased morbidity, disability, and mortality (CDC, 2011; National Diabetes Information Clearinghouse [NDIC], 2007). In fact, diabetes is the $7^{\text {th }}$ leading cause of death in adults in the United States; adults with T2D have two to four times higher rates of death due to heart disease and are at two to four times greater risk for stroke (CDC, 2011). Additionally, comorbidities with T2D are common. Approximately $75 \%$ of adults with diabetes also have hypertension (NDIC, 2007). Diabetes is the leading cause of blindness in adults 20 to 74 years of age and the leading cause of all kidney failure, accounting for $44 \%$ of all kidney failures in 2008 (CDC, 2011; NDIC, 2007). More than $60 \%$ of nontraumatic lower-limb amputations involve people with diabetes (CDC, 2011; NDIC, 2007). Older adults with diabetes also are two to three times more likely to report decreased physical functional ability (NDIC, 2007; CDC, 2011). Thus, T2D represents a major health concern.

The risks of disability, morbidity and mortality associated with T2D can be reduced through self-management of the disease (National Diabetes Education Program [NDEP], 2009). Research focusing on self-management of T2D has shown several correlates including higher income and education, gender (i.e., being female), having more disease knowledge, and having higher disease-specific self-efficacy. Research suggests that interventions targeted to improve the psychosocial variables, particularly self-efficacy, may be an effective means to improve selfmanagement of T2D (Cherrington, Wallston, Rothman, 2010; Sarkar, Fisher, Schillinger, 2006). 
An emerging construct referred to as health literacy, described as literacy skills needed to navigate health care situations, also may influence self-management in T2D, but has not been fully examined empirically. 


\section{Literature Review}

\section{Type 2 Diabetes}

Diabetes is a metabolic disorder that results in blood glucose levels that are too high and leads to difficulty converting food into needed energy (NDIC, 2008). There are three main types of diabetes, including type 1 diabetes, type 2 diabetes (T2D) and gestational diabetes (NDIC, 2008). T2D, formerly known as "adult-onset diabetes," generally starts due to the body's inability to use the insulin that the pancreas is providing (NDIC, 2008). T2D often is diagnosed by an HbA1c (glycated hemoglobin) laboratory blood test which shows average blood-glucose levels over the past three months (NDIC, 2008). An HbAlc test value of lower than 5.7\% is considered normal, $5.7 \%$ to $6.4 \%$ indicates pre-diabetes, and a test value of $6.5 \%$ or higher is indicative of diabetes (A.D.A.M. Medical Encyclopedia, 2011).

\section{Risk Factors for T2D}

In the United States, there are about 23.6 million people (7.8\%) who have diabetes, 90 to $95 \%$ of whom have T2D (NDIC, 2007). Approximately $11.2 \%$ of men have diabetes and 10.2\% of women have diabetes. Increased risk for T2D onset is associated with a variety of factors with some being fixed (i.e., family history, race/ethnicity, and older age) and other factors being modifiable (i.e., overweight/obesity, hypertension, previous history of gestational diabetes in females, and physical activity less than three times a week ; NDEP, 2009; Riddle \& Genuth, 2010).

Family history is considered a risk factor if there are first-degree relatives with T2D. Additionally, as compared to non-Hispanic whites, the risk of diabetes is $18 \%$ higher in Asian Americans, 66\% higher among Hispanics, and 77\% higher among non-Hispanic blacks (CDC, 
HEALTH LITERACY 4

2011). In addition to hypertension, a history of vascular disease has been linked to development of T2D (Spollett, 2006).

Regarding age, adults over aged 60 have the highest prevalence rates of diabetes, with $23.1 \%$ of adults aged 60 or older having diabetes. Additionally, those who have a body mass index greater than or equal to 25 ( $\geq 23$ for Asian Americans or $\geq 26$ for Pacific Islanders) have an increased risk for developing T2D (NDEP, 2009). Given the increase in fat mass, loss of muscle mass, redistribution of body fat, and height shrinkage with age, older adults are at an increased risk for being overweight or obese (Biggs et al., 2010). Up to 70\% of adults 60 years and older in the United States are considered overweight or obese, as measured by BMI. Thus, increasing age paired with increases in weight put older adults at a higher risk for developing T2D.

\section{Self-Managing T2D}

The key to self-management of T2D is to maintain a healthy blood-glucose level of less than 7\% (A.D.A.M. Medical Encyclopedia, 2011; Riddle \& Genuth, 2010). Most people with T2D are able to control their blood glucose by eating healthy meals low in fat and calories, getting at least 30 minutes of moderate exercise three times a week, achieving and maintaining healthy weight, and taking oral insulin medications (NDIC, 2007; Riddle \& Genuth, 2010). Some individuals with T2D may need to use insulin injections to aid in controlling their blood glucose (NDIC, 2007; Riddle \& Genuth, 2010).

Appropriately self-managing blood glucose can reduce the risk for complications related to diabetes. It has been found that for every percentage point drop in A1C levels can reduce the risk for microvascular complications by $40 \%$ (NDIC, 2007). In addition to adequate glucose 
control, for every $10 \mathrm{~mm} \mathrm{Hg} \mathrm{reduction} \mathrm{in} \mathrm{systolic} \mathrm{blood} \mathrm{pressure} \mathrm{risk} \mathrm{for} \mathrm{complications} \mathrm{are}$ reduced by $12 \%$ (NDIC).

Additional considerations for managing T2D exist for older adults. Specifically, comorbidities may result in physical limitations that may require adjustment in self-management goals and interventions (NDEP, 2009; Riddle \& Genuth, 2010; Spollett, 2006). Comorbidities, such as rheumatoid arthritis, also may contribute to inaccurate timing of medication-taking and dosing errors due to managing several other medications. Older adults with T2D and their health care providers must be vigilant against drug interactions (Spollett, 2006). Since older adults tend to have more irregular food intake, slowed absorption of nutrients in the intestines, and because of some medications (e.g. beta-blockers), older adults have difficulty avoiding hypoglycemia (Spollett, 2006).

\section{Psychosocial Predictors of Self-Management in T2D}

There have been a variety of constructs found to be related to diabetes self-management including social support, daily burden, and coping style. However, two psychosocial variables have frequently been identified as predictors of diabetes self-management and glycemic control self-efficacy and negative affect (Nakahara et al., 2006; Schillinger et al., 2002; Sousa, Zauszniewski, Musil, Price Lea, \& Davis, 2005; Tang, Pang, Chan, Yeung, \& Yeung 2007; Xu, Toobert, Savage, Pan \& Whitmer, 2000).

Self-Efficacy. Self-efficacy can be described as an individual's belief that they can execute actions required to deal with situations (Bandura, 1982). How an individual perceives their ability to successfully perform a task (e.g., changing their diet) can affect the type of outcome that they expect (e.g., weight gain, loss, or no change). Self-efficacy, also, can impact 
HEALTH LITERACY 6

behavior by influencing perception of barriers as well as the amount of time and effort expended for a task (Bandura, 1982; 2005). Self-efficacy has been found to increase through childhood and young adulthood, peaking during middle adulthood and then gradually declining at around 60 years of age (Gecas, 1989).

When measuring self-efficacy within the T2D population, diabetes-specific self-efficacy is generally used to assess rather than general self-efficacy. Positives associations between disease-specific self-efficacy and self-management of T2D have been well established (Sarkar, Fisher, \& Schillinger, 2006; Sousa et al., 2005; Xu et al., 2007). In a 12-month longitudinal study by Nakahara and colleagues (2006) of 256 Japanese adults with T2D ( $M$ age $=62.3$ ), it was found that diabetes-related self-efficacy was the only variable to directly and positively be related to adherence to diabetes regimens $(r=.90)$. However, there were some limitations with this study. Firstly, participants were recruited from an institute specializing in diabetic treatment and research, thus they may have had additional help in maintaining better adherence and treatment than the general population. Additionally, culture is not taken into account, such that culturally held beliefs about the role of the individual in health care are not addressed. In spite of the limitations, this study demonstrates how disease-specific self-efficacy can be related one's adherence to medical regimen in T2D.

Another study used a randomized trial for a diabetes education program in a sample of 463 obese adults aged 25 to 75 years with T2D to investigate the role of several psychosocial variables and demographics on self-management behaviors and glycemic control (King et al., 2010). King and colleagues found that diabetes-related self-efficacy, problem solving, and social-ecological support increased the variance accounted for in self-management behaviors. Those with higher self-efficacy, who used more problem solving, and had more perceived 
support engaged in more self-management. However, only diabetes-related self-efficacy specifically, behavior-specific self-efficacy - and problem solving were found to be independently associated with self-management (King et al.). Nevertheless, there were some important limitations to this study. The sample was recruited through a single health care organization, reducing ability to generalize to those with lower education or economic status. Lastly, the study used only baseline data, reducing the ability to form causal relations between variables of interest. Despite the limitations, the study provides another good example of the role of diabetes-related self-efficacy in self-management of T2D. Thus, self-efficacy is an important construct to include when examining self-management of T2D because of its relation to how one perceives their ability to successfully manage the disease. However, disease-specific selfefficacy has not been investigated thoroughly when focusing on mid- and late-life specifically, with the majority of studies including a sample of younger and/or older adults.

Negative Affect. Studies have found that negative affect (e.g., depression) can also be related to poor self-management of diabetes. It has been established that adults with T2D tend to have higher rates of depression. A meta analysis by Anderson, Clouse, Freedman, and Lustman (2001) found that when analyzing 42 studies with a combined sample size of 21, 351 individuals with T2D were twice as likely to have depression $\left(\mathrm{OR}=2.0,95 \% \mathrm{CI} 1.8-2.2, \chi^{2}=159.8, p<\right.$ $.0001)$ in the 18 controlled studies that were analyzed. In the eight studies that examined lifetime prevalence of major depression, it was found that those with diabetes had significantly higher prevalence of depression. Specifically, $17.5 \%$ of individuals with diabetes had met the diagnostic criteria for major depression at any point in their life, as compared to $6.8 \%$ of those without diabetes who met the diagnostic criteria for major depression (Anderson et al.). 
This meta analysis identified several limitations in the literature, however there was one issue that impeded accurate examination of depression in individuals with diabetes. Many studies were found to lack differentiation between types of diabetes, making it difficult to determine the exact rates of major depression among those with T2D (Anderson et al., 2001). Conversely, the meta analysis as a whole had some limitations. Firstly, an inherent limitation is publication bias, making it difficult to include all relevant studies that may not have significant results. Secondly, the meta analysis included many studies with small samples making it difficult to conduct some of the more complex multivariate analyses. Lastly, the majority of the studies did not use population-based samples and recruited from clinics and medical centers. Despite the limitations of this meta analysis, it deftly portrays the rates of depression in the diabetic population.

The actual mechanisms by which negative affect is related to self-management of diabetes are not precisely known and are beyond the scope of this study. However, one explanation pinpoints having a history of depression leads to an increased risk for T2D due to a more sedentary lifestyle and engagement in unhealthy behaviors (e.g., smoking). Another thought is that there is a dynamic relation between physiological effects depression and T2D. Specifically, depression may reduce glucose uptake and increase insulin resistance. Conversely, poor diabetes control may cause or worsen depression and reduce the effect of antidepressants (Katon, 2008).

Depressive symptoms have been linked to poorer self-management, as well as higher complication rates including retinopathy, nephropathy, macrovascular complications and sexual dysfunction (e.g., Ciechanowski, Katon, \& Russo,2000; Lustman, Penckofer, \& Clouse, 2007; Park, Hong, Lee, Ha \& Sung, 2004). In a large cross-sectional study of 879 adults with T2D recruited from primary care clinics, Gonzalez and colleagues (2007) found that those who were 
considered to likely have major depression, as compared to those unlikely to have major depression, were significantly less adherent. For example, those likely to have major depression were adherent to general dietary recommendations 3.8 days as compared to those not likely to have major depression, who were adherent an average of 4.6 days (Gonzalez et al.). Additionally, participants likely to have major depression engaged in less exercise than recommended, exercising an average of 2 days; while participants who were unlikely to have major depression exercised an average of 2.8 days (Gonzalez et al.). Lastly, participants considered likely to have major depression engaged in less self-monitoring of blood glucose, an average of 2.8 days, than those who were considered unlikely to have major depression, who averaged 3.6 days of adherence. Despite the cross-sectional nature of the study, this is one of the few studies to control for prescription use for depression, allowing for a more accurate measure of depression and depressive symptamology.

Lastly, similar results were found by Lin and colleagues (2004) in an epidemiologic survey in which 4,463 adults were recruited from a large health management organization, those with major depression performed fewer diabetes-related self-care activities than those who did not have major depression. All mean odds ratios were between 1.3 and 2.1 and demonstrated that those with major depression were less likely to eat healthy, engaged in less physical activity, engaged in fewer specific exercise routines, and were more likely to smoke (Lin et al.). As was found by a meta analysis by Anderson and colleagues (2001), a limitation was the use of a health management organization as the sole recruitment source instead of using a population-based sample. Additionally, use of prescription medications for depression was not controlled for in the study. However unlike other studies that used self-report data, Lin and colleagues also utilized 
clinical and pharmacy data to measure adherence. In spite of its limitations, this study demonstrates a more detailed picture of adherence with in the diabetes population.

Even with the current issues in the literature concerning control for medication use for depression the tendency to recruit from medical samples, negative affect can important with regards to self-management of T2D. Whether it is because of the lethargy or sense of helplessness associated with depressive symptomatology, negative affect can be detrimental to adequate self-management of this disease. This possibility makes it an important concept to investigate when considering self-care in T2D.

\section{Health Literacy}

In addition to self-efficacy and diabetes-related distress, health literacy is an emerging construct that may be important in self-management in T2D. As opposed to general literacy - an individual's ability to read, write, and understand information - health literacy is specific to health care contexts (Nath, 2007). Thus, health literacy can be described as an individual's ability to understand and acquire health information in order to make appropriate decisions regarding healthcare and services (Kutner, Greenber, Jin, \& Paulsen, 2006). Additionally, health literacy can be seen as a means to enable individuals to have greater control over their health and determinants of health (i.e., personal, social, and environmental; Nutbeam, 2008)

In general, researchers and clinicians refer to four levels of health literacy including below basic, basic, intermediate, and proficient health literacy (Kutner et al., 2006). The lowest level is below basic, which indicates that the individual only has the minimal health literacy skills. Basic health literacy signifies the individual has the skills necessary for everyday medically related literacy activities. Intermediate health literacy describes an individual as 
having skills necessary to engage in fairly challenging literacy activities with regards to health care. Lastly, proficient health literacy characterizes the individual as having the abilities to perform complex literacy activities regarding health care. The 2003 National Assessment of Adult Literacy found that approximately $14 \%$ of adults have below basic health literacy, $22 \%$ have basic health literacy, $53 \%$ of adults have intermediate levels of health literacy, and $12 \%$ have proficient health literacy (Kutner et al., 2006). Thus, having adequate health literacy implies the ability to problem-solve and make decisions to apply new information to function as a health care consumer (Nath, 2007).

Age differences in health literacy have been observed. Specifically, adults ages 65 and older tend to have lower health literacy than their younger counterparts (Kim, 2009; Kim, Love, Quistberg \& Shea, 2004; Schillinger et al., 2002). Gazmararian and colleagues (1999) found that in a sample of 3,260 new Medicare enrollees aged 65 and older, 33.9\% of English-speaking participants had inadequate or marginal health literacy. They also reported that higher rates of inadequate health literacy were associated with older age, being black, having fewer years of education, and having a blue-collar work history. Lastly, they found a trend in age regarding the prevalence of inadequate health literacy, with $15.6 \%$ of participants aged $65-69$ to $58 \%$ of those aged 85 and older having inadequate health literacy. In fact, when controlling for education and cognitive impairment, participants 85 years and older were 8.6 times more likely than younger participants to have inadequate or marginal health literacy. There was one major limitation for this study. Given that the majority of non-responders were older and had higher income levels, prevalence of low health literacy may have been underestimated (due to lack of older responders) or overestimated (due to lack of lower income participants). Generally, it has been found that 
there is some evidence of age being related to health literacy; however, aside from other demographic information, other factors have not been well investigated (e.g., cognition).

There is no consensus on gender differences in health literacy. Specifically, a study found that women tend to have higher health literacy scores than men, with a higher percentage of men having below basic health literacy (Kutner et al., 2006). However, there are mixed results in regards to gender with other studies failing to find significant differences (Kim et al., 2004; Kim, 2009; Rudd, 2007) or finding that females have lower health literacy (Schillinger et al., 2002).

Race and ethnicity differences have been reported in health literacy, with ethnic and racial minorities usually having lower levels (Osborn, et al., 2009; Rudd, 2007). Hispanic adults tend to have lower health literacy than other racial groups, with $41 \%$ of Hispanic, $25 \%$ of American Indian/Alaska Native, 24\% of Black, 13\% Asian/Pacific Islander, and 9\% of White adults having inadequate health literacy (Kutner et al., 2006). Additionally, educational differences in health literacy also are observed (Bosworth, 2010; Gazmararian et al., 1999; Kim et al, 2004; Kim, 2009; Rudd, 2007; Schillinger et al., 2002). Adults who have not attended or completed high school, or are not currently in school tend to have lower health literacy, including a high percentage with below basic health literacy (Kutner et al., 2006).

Finally, income level has been associated with level of health literacy (Bosworth, 2010; Federman et al., 2009; Gazmararian et al., 1999; Kim et al, 2004.; Kim, 2009; Rudd, 2007). Adults who live below the poverty level tend to have lower health literacy than those who live above the poverty line (Kutner et al., 2006). Overall, low health literacy is highest in those without a high school education, ethnic/racial minorities, those who live below the poverty line, and older adults. 
HEALTH LITERACY 13

Low health literacy has been linked to poorer health outcomes. Specifically, low health literacy has been found to be linked to poorer medication adherence, lower levels of knowledge about chronic disease and health services, and poorer disease management (e.g., glycemic control; Nath. 2007). One cross-sectional study of 68 adults with T2D recruited from a general internal medicine clinic found that health literacy was significantly associated with participants' most recent $\mathrm{HbA1c}$ even after controlling for education, age, gender, race, and treatment regimen (Powell, Hill, \& Clancy, 2007). Specifically, those with lower health literacy had HbA1c levels $1.21 \%$ to $1.36 \%$ higher than those with a health literacy level corresponding to an education level of $9^{\text {th }}$ grade or higher.

Given that studies have demonstrated a poor match between the diabetic population and readability of diabetes-specific printed materials, internet resources, and interactive multimedia programs, health literacy needs to be better understood within this population (Nath, 2007). However, establishing a direct link between health literacy and chronic disease management has proven to be difficult. Specifically, discovering the degree that health literacy mediates adverse effect or is a proxy for more direct mediating variables (e.g., self-efficacy and negative affect) is not clear (Bosworth, 2010)

\section{Summary}

Diabetes is recognized as one of the leading causes of mortality and disability (NDIC, 2008). It is also associated with long-term complications including stroke, nerve damage, and kidney failure. T2D tends to affect certain populations (e.g., overweight/obese), but especially middle-aged and older adults. Successful management of this disease involves diligent selfmanagement and life-style changes that may be a challenge for those of the aging population. 
HEALTH LITERACY 14

Self-efficacy has been linked to self-management of diabetes, influencing self-care behaviors such as exercise and diet. Negative affect, specifically distress, can negatively affect self-management because of the possible lack of motivation or energy to perform such tasks. Health literacy has been examined as a predictor of self-management for diabetes because of the implications of being able to understand elements of healthcare plans and the disease (Baker et al., 1999). Although there has been a great deal of research including these individual constructs on the self-management of T2D, there has not been much on how they relate to each other. Specifically how or if health literacy may interact with one construct in order to affect an individual's distress related to their diabetes and how efficacious they feel about maintaining their disease. Because of the increasing aging population, research on how this population is able to self-manage this disease with regards to health literacy and psychosocial constructs is an important consideration.

Thus, the aims of the study were:

1. To examine the associations between health literacy and self-management behaviors in T2D. Specifically, attempt to ascertain the importance of health literacy in engagement in diabetes self-management activities;

2. To gain a better understanding of the relation of diabetes-related self- efficacy and negative affect on engagement in diabetes self-management activities. Low selfefficacy and high negative affect have been linked to less adherence to diabetes selfmanagement. Thus, these two constructs are essential to investigate factors that may affect glycemic control.

3. To examine the relation of health literacy and self-efficacy in the context of other known predictors of self-management behavior. Since some demographic variables 


\section{HEALTH LITERACY 15}

have been linked to diabetes self-care activities (i.e., age), it was important to establish how those variables affect self-management of T2D. 


\section{Research Questions and Hypotheses}

The study examined the influence of age, health literacy, diabetes-related self-efficacy, and diabetes-related emotional distress on adherence to diabetes self-care activities. There were three exploratory questions that were examined:

1. Due to the equivocal findings for gender and health literacy, the associations between gender and health literacy were examined as an exploratory question.

2. Given the lack of consistent findings concerning the role of length of diagnosis, the possible effect of length of diagnosis was examined in relation to self-management as an exploratory question (e.g., Karter, Ferrara, Darbinian, Ackerson, \& Selby, 2000;

Polonsky, Fisher, Guzman, Philis-Tsimikas, \& Edelman, 2010).

3. The associations between the NVS, portions of the Everyday Cognition Battery (ECB) Subscales of Inductive Reasoning and Knowledge Test, and Diabetes Knowledge Test (DKT) were examined to test the NVS's relation similar measures. Additionally, five hypotheses were examined :

1. Age was expected to be negatively associated with health literacy (e.g., Kim, 2009; Kutner, et al., 2006; Rudd, 2007).

2. Diabetes-related self-efficacy was expected to be positively associated with diabetes self-care activities (e.g., Cherrington, Wallston, \& Rothman, 2010; King et al., 2010). Specifically, individuals with higher diabetes-related self-efficacy would report more self-care activities. See Figure 1 for conceptual model.

3. Diabetes-related emotional distress was expected to predict self-care activities. (e.g., Delahanty et al., 2007; Gonzalez et al, 2007). Specifically, those who score higher on the 
emotional distress would participate in less self-care activities. See Figure 1 for conceptual model.

4. Health literacy was expected to predict adherence to self-care activities (e.g., Osborn et al., 2009; Tang et al., 2007). Specifically, those who report higher levels of health literacy also would report more self-care activities. See Figure 1 for conceptual model.

5. Health literacy was expected to mediate the effects of self-efficacy on engagement in diabetes self-care behaviors (e.g., Sarkar, Fisher, \& Schillinger, 2006). See Figure 1 for conceptual model.

6. Health literacy was expected to mediate the effects of diabetes-related distress on engagement in diabetes self-care behaviors (e.g., Sarkar, Fisher, \& Schillinger, 2006). See Figure 1 for conceptual model. 


\section{Participants}

\section{Methods}

There were two criteria required for participation: (a) individuals had to be 40 years of age or older and (b) had a diagnosis of type 2 diabetes. Participants were recruited through Syracuse University's StudyResponse research recruitment system and through advertisement on Amazon.com's Mechanical Turk, which allows businesses and researchers access to an ondemand population in order to complete tasks (e.g., transcribing audio recordings) and participate in research studies. Those adults who completed the study were offered a small (\$10) honorarium as a token of appreciation. In order to be included in subsequent analyses, participants had to have reported age, gender, and inaccurate participant identification number given to them by StudyResponse or Mechanical Turk. Additionally, participants had to have reported at least two of three items concerning their diabetes diagnosis and hemoglobin A1 levels (i.e., date of diagnosis, date of last $\mathrm{HbAlc}$ test, and date of next $\mathrm{HbAlc}$ test). A total of $65^{1}$ adults ages 40 and older participated. A power analysis indicated that for the four predictors (age, health literacy, diabetes-related distress, and diabetes-related self-efficacy), an $N=60$ is sufficient to provide power $($ power $=.80)$ to detect a medium effect size $\left(f^{2}=.25\right)$ at $p<.05$. A post hoc power analysis revealed that for a sample size of 65 and an effect size $f^{2}=.25$, the statistical power was $.89, F(4,60)=2.52$.

The mean age of the participants was 51 years $(\mathrm{SD}=6.71)$, with ages ranging from 40 to 66 years of age. The average length of time since diagnosis of T2D was 68.5 months, or 5.5

\footnotetext{
${ }^{1}$ Note: There were changes in the sample originally proposed to be recruited. Specifically, instead of adults aged 45 and older who have had T2D for three to six months, recruitment of adults aged 40 and older with no diagnosis cutoff was implemented with IRB and committee approval. This change was initiated due to screening errors by StudyResponse who invited ineligible participants (aged less than 45 years) and because the majority of the participants did not meet the diagnosis cutoff of the 65 of 70 participants requested to be invited to participate. No meaningful differences on variables were found between StudyResponse and Mechanical Turk participants. A recruitment diagram is presented in Appendix A.
} 
years. Of the sample, $50.8 \%$ were female. Within the sample, $84.6 \%$ were Caucasian/White, 9.2\% African American/Black, 1.5\% Native Hawaiian or Other Pacific Islander, and 3.1\% other (i.e., Hispanic). One participant (1.5\%) did not report race. The majority of the sample was married (76.9\%), although $6.2 \%$ were widowed, $10.8 \%$ were divorced, and another $6.2 \%$ were single, never married. In terms of difficulty paying bills, $20 \%$ reported having 'no difficulty', $27.7 \%$ reported having 'a little difficulty', $33.8 \%$ reported having 'some difficulty', and 16.9\% reported having 'a great deal of difficulty'. One participant did not report their difficulty paying bills. Additional descriptive data are presented in Table 1.

The majority of the participants reported having no current problems related to their diabetes (80\%). To determine body mass of the current sample, Body Mass Index (BMI) was calculated by [Weight in pounds/ (Height in Inches) ${ }^{2} * 703$ ]. Of the 53 participants with all the information to calculate their BMI, the average was 28.73 , which is considered overweight (BMI between 25.0 and 29.9; CDC, 2011). To attain a more detailed BMI distribution, the sample was split into groups based on the World Health Organization's (WHO) BMI classifications (WHO, 1995 ) including: Severely Underweight (<15), Moderately Underweight (15 to 16), Mildly Underweight $(>16$ to $<18.5)$, Healthy/Normal Weight $(18.5$ to $<25)$, Overweight $(25$ to $<30)$, Moderately Obese ( 30 to $<35$ ), Severely Obese ( 35 to $<40$ ), and Very Severely Obese $(\geq 40)$. Within the current sample reporting enough information to calculate BMI $(n=53), 1.5 \%$ were severely underweight, none were moderately underweight, $3.1 \%$ were mildly underweight, $18.5 \%$ were a healthy weight, $24.6 \%$ were overweight, $20 \%$ were moderately obese, $9.2 \%$ were severely obese, and $4.6 \%$ were very severely obese. 
HEALTH LITERACY 20

\section{Measures}

Participants were asked to provide demographic information. Additionally, healthspecific information was obtained (see Table 2), which included: current problems with diabetes, results of last HbA1c test, how long they've been diagnosed with T2D, BMI, and occurrence of any other health conditions.

Summary of Diabetes Self-Care Activities Measure (SDSCA; Toobert et al., 2000) served as the dependent variable in this study. This 11-item self-report measure assesses five regimen areas including five items about diet, two items addressing exercise, two about bloodglucose testing, and two items regarding foot care. Higher scores indicate more engagement in self-care activities. In both randomized interventions and observational studies, the SDSCA has shown satisfactory internal consistency (average inter-item correlations $=0.47$ ). Moderate testretest reliability also has been demonstrated (average $r \mathrm{~s}=0.40$; Toobert et al., 2000). For this sample $(n=60)$, Cronbach's $\alpha=.78$. Mean number of days this sample engaged in self-care activities was 4.1 (e.g., Gonzalez et al., 2007). Means and standard deviations are presented in Table 3. See Appendix B for a copy of the SDSCA.

Diabetes Empowerment Scale-Short Form (DES-SF). This is an 8-item measure to assess diabetes-related self-efficacy with higher scores indicating higher diabetes-related selfefficacy. This scale has been found to be reliable $(\alpha=.84)$ using the original dataset of the DES and .85 with a new sample recruited to test the DES-SF (Anderson et al., 2003). The DES has been found to have satisfactory concurrent validity as evidenced by correlations of the DES subscales as related to the Diabetes Care Profile subscales (Anderson et al., 2003). The DES also has been found to have good 6-week test-retest reliability $(r=.79)$. Additionally, the DES-SF was found to have content validity in a study of 229 participants, evidenced by DES-SF scores 
HEALTH LITERACY 21

and $\mathrm{HbA} 1 \mathrm{c}$ levels changing in a positive direction after a 6-week patient education program (Anderson et al., 2003). With the current sample $(n=63)$, the DES-SF had a Cronbach's alpha of .82. The current sample had a mean score of 4.2 , which has been demonstrated in other studies (e.g., Nam, Chesla, Stotts, Kroon, \& Janson, 2010). The means and standard deviations of the sample are presented in Table 3. See Appendix C for a copy of the DES-SF.

Problem Areas in Diabetes Scale (PAID). This 20-item scale is a self-report measure of diabetes-related negative emotions. Items are rated on a 6-point Likert scale ranging from 0 ('not a problem') to 5 ('serious problem') (Snoek, Pouwer, Welch \& Polonsky, 2000).The items are scored to range between $0-100$, with higher scores indicating greater emotional distress. This scale has been found to have good internal consistency $(\alpha=.93-.95)$ and factorial validity crossculturally (Polonksy et al., 1995; Snoek, Pouwer, Welch, \& Polonsky, 2000). Item-to-item correlations ranged from 0.32 to 0.84 with a mean of 0.68 . Tests of concurrent validity have indicated that the PAID is significantly related with similar psychosocial measures (e.g., general emotional distress), regimen adherence, short- and long-term diabetic complications and glycemic control greater than or equal to one year later (Polonsky et al., 1995). For the current study, a Cronbach's alpha of .97 was found in the sample $(n=60)$. Additionally, the mean for the sample was 51.7, which is somewhat lower than some studies have found (Polonsky et al., 1995; Snoek, Pouwer, Welch, \& Polonsky, 2000). Means and standard deviations can be found in Table 3. See Appendix D for a copy of the PAID.

The Newest Vital Sign (NVS; Johnson \& Weiss, 2008). The NVS was used as the index of health literacy. This scale is a brief instrument used to assess health literacy abilities by participants actively reading and demonstrating understanding of information on a nutrition label (Johnson \& Weiss, 2008; Weiss et al., 2005). The NVS is a 3-minute assessment containing a 
nutrition label and six questions pertaining to the label (Weiss et al., 2005).The NVS assesses prose literacy (i.e., interpreting ingredients), document literacy (i.e., interpreting nutrition facts table of label) and quantitative literacy (i.e. interpreting percentage daily values and using numbers on label). Level of health literacy was determined by several cutoffs: $0-1$ is considered inadequate, 2-3 is considered limited, and 4-6 is considered adequate. For the current sample, $6.2 \%$ had limited health literacy, $29.2 \%$ had inadequate health literacy, and $64.6 \%$ were considered to have adequate health literacy. The NVS has been demonstrated to be internally consistent (Cronbach's $\alpha=.76$; Weiss et al., 2005) and criterion validity by measuring correlations with TOFHLA scores $(r=.59, p<.001$; Weiss et al., 2005). Within the current sample $(n=62)$, a Cronbach's alpha of .91 was found. Furthermore, a mean score of 3.8 out of 6 correct was found in the current sample, which is consistent with literature (e.g., Johnson \& Weiss, 2008; Patel et al., 2011; Weiss et al., 2005). Means and standard deviations can be found in Table 3. See Appendix E for copy of The NVS.

Diabetes Knowledge Test (DKT). This is a 23-item scale to measure diabetes-related knowledge (Fitzgerald et al., 1998). It includes 14 items that are appropriate for adults with type 1 diabetes (T1D) and T2D and a 9-item subscale regarding insulin use. This measure has been found to be reliable for the 14-item general section (Cronbach's $\alpha=.71$ ) and for the 9-item insulin use subscale (Cronbach's $\alpha=.75$; Fitzgerald et al., 1998). This measure also has found to be valid in community and health department samples of T1D and T2D. A Cronbach's alpha of .86 was found in the current sample $(n=56)$. As shown in Table 3 , the mean for the current sample was 14.2 out of 23 , or $62 \%$, correct which is comparable to other studies utilizing the DKT (e.g., Powell, Hill, \& Clancy, 2007). See Appendix F for a copy of the DKT. 
HEALTH LITERACY 23

Everyday Cognition Battery (ECB). This measure assesses four cognitive abilities within three every-day, real world domains (Allaire \& Marsiske, 1999). Two of the four most relevant subscales were used for the purposes of this study. The 42-item Inductive Reasoning Test was used to assess ability to identify information patterns in every-day printed material and use that information to answer questions within three domains (i.e., medication use, financial management and food preparation and nutrition). For the purposes of this study, only 30 items regarding medication use and food preparation and nutrition were used due to their relevance. Additionally, the 30-item Knowledge Test was utilized to assess domain-relevant knowledge in medication use, financial management, and food preparation and nutrition. For the purposes of this study, only 20 items were used to because of relevance.

It has been found that each test within the entire ECB has good internal validity (Inductive Reasoning Test, $\alpha=.88$; Knowledge Test, $\alpha=.69$; Declarative Memory Test, $\alpha=.81$; Working Memory Test, $\alpha=.72$; Allaire $\&$ Marsiske, 1999). This measure also has been found to be have convergent and divergent validity as evidenced by moderately strong, positive correlations between the ECB tests and basic cognitive ability tests (Letter Sets Test, Number Series Test, Verbal Meaning Test, Hopkins Verbal Learning Test and Computation Span Task; $r \mathrm{~s}=.26$ to .75$).$ For the items used in the current study, scores could range from $0-60$ for the Inductive Reasoning Test and from 0-40 for the Knowledge Test. In the present study, a Cronbach's alpha of $.92(n=59)$ was found for the 30 items used in from the Inductive Reasoning Test. Additionally, a Cronbach's alpha of .69 $(n=58)$ was found for the 20 items utilized from the Knowledge Test. In the current sample a mean of 40.1 for the ECB Reasoning items and a mean 12.2 for the ECB Knowledge items correct. Means and standard deviations for the 30-item Inductive Reasoning and 20-item Knowledge Tests can be found in Table 3. See 
HEALTH LITERACY 24

Appendix G for a copy of the ECB Subscales of the Inductive Reasoning and Knowledge Test items.

\section{Procedure}

Participants completed all measures via Survey Monkey, an online data collection survey-hosting service. Participants reported their diabetes-specific self-management activities by way of the SDSCA and completed the NVS to assess functional health literacy. Additionally, participants rated their perceived diabetes-related self-efficacy by completing the DES-SF. Also, participants completed the ECB Subscales of Inductive Reasoning and Knowledge Test items pertaining to medication use, food preparation, nutrition, and medical finances. Participants completed the DKT to assess their knowledge of diabetes. Participants, then, rated their diabetesrelated distress by way of the PAID. Lastly, they answered an open-ended question about current problems with their diabetes, “Are you currently having problems with your diabetes?” They also reported demographic information (e.g., age, sex, health status; See Appendix G). Measures were organized in this order to allow more accurate reporting of self-care activities. Specifically, the SDSCA was placed first to minimize the Diabetes Knowledge Test affecting their self-care reports. Additionally, the PAID was placed second to last to minimize how reflecting on negative affect related to their diabetes affected response to the SDSCA. Additionally, the PAID was placed before the NVS to minimize negative affect on the performance on the health literacy measure. Lastly, demographics were placed at the end given that these items are not influenced by fatigue ( Dillman, 2000). 
HEALTH LITERACY 25

\section{Results}

\section{Preliminary Analyses}

Data were examined for multivariate outliers by examining Mahalanobis Distances, leverage values, and examining Cook's D values. It was found that the dataset met all assumptions for the general linear model. To determine the amount of missing data in the sample, frequencies were conducted on all variables of importance. Participants were excluded if they had missing age $(n=99)$, gender $(n=99)$, and had a missing or invalid participant identification number given to them by StudyResponse or Mechanical Turk $(n=11)$.

Additionally, if participants were missing or had invalid two or more of the three items referring to diabetes information (i.e., date of last HbAlc test, date of next HbAlc test, when diagnosed), they were excluded from final analyses $(n=29)$. Lastly, if participants did not complete the majority of the measure items, they were excluded from the final analyses (i.e., NVS, $n=2$; SDSCA, $n=0$; PAID, $n=7$; and DES-SF, $n=6$ ) Any demographic (e.g., age) or health variables (e.g., length of diagnosis) that were found to be significantly related to diabetes self-management in correlations and $t$-tests were included in subsequent regression models and post-hoc analyses. Additionally, variables found to be important to diabetes self-management in the literature also were included in subsequent regression models and post-hoc analyses.

\section{Exploratory Analyses}

To test the first exploratory question concerning whether health literacy scores were comparable or disparate between males and females, a $t$-test was conducted to determine if scores differed significantly between each group. A significant difference was found between males and females, $t(63)=2.57, p=.013$, with females $(M=4.52, S D=2.11)$ having higher 
health literacy scores than males $(M=3.06, S D=2.45)$. More specifically, females were found to have adequate health literacy scores (approximately 4-6 items correct), while males tended to have limited health literacy scores (approximately 2-3 items correct).

To test the second exploratory question, a t-test was conducted to examine whether there was a significant difference in diabetes self-management differed based on length of diagnosis, activities between those who have had T2D for less than 5 years $(n=34)$ and 5 years or more $(n$ =31). No significant difference was found between the groups concerning self-care activities, with those who have had T2D less than 5 years $(m=4.12, s d=1.53)$ and those who have had T2D 5 years or greater $(m=4.14, s d=1.53)$ having equivalent self-management.

For the third exploratory analysis examining whether the NVS was significantly correlated with similar measures, the ECB Inductive Reasoning and Knowledge Tests and the Diabetes Knowledge Test, Pearson's Product-Moment Correlations were conducted (see Table 4). It was found that all measures were significantly and positively correlated, $r s$ (65) ranged from .705 to .841 .

Additionally, given that age is an important demographic with relation to diabetes selfmanagement and its correlates, Pearson's Product-Moment Correlations were conducted to examine the relation of age to other variables of interest (presented in Table 4). It was found that age was negatively associated with diabetes related distress $(r=-.324, p<.05)$ suggesting that increasing age is related to lower diabetes-related distress. Age also was positively related to ECB Knowledge $(r=.371, p<.005)$, suggesting that as age is related to higher every-day cognitive knowledge. Lastly, age was found to be negatively associated with self-management activities $(r=-.246, p=.049)$, suggesting that frequency of self-management activities decreases with age. 


\section{Hypothesis Testing}

To address the first hypothesis, to determine whether health literacy was negatively associated with age — as has been well documented in the literature — a Pearson's ProductMoment Correlation was conducted. Health literacy was significantly and positively associated with age, $r=.345, p=.005$. This finding suggests that older adult is related to higher levels of health literacy. To address the second, third, and fourth hypotheses' predictions that (H2) participants with higher diabetes-related self-efficacy and (H3) participants with higher health literacy would report more frequent engagement in self-care activities and (H4) participants with higher diabetes-related distress would engage in less self-management, a hierarchical regression was conducted. Given that age and gender have been linked to health literacy and diabetes selfmanagement and were found to be the only demographics significantly associated with those variables, they were imputed in the first step to control for any effects. Based on literature demonstrating that diabetes-related distress and self-efficacy are related to diabetes selfmanagement, these two variables were entered in Step 2. Lastly, given the lack of research regarding health literacy's role in diabetes self-management after taking diabetes-related distress and self-efficacy into account, health literacy was entered in the third and final step of the model in order to determine its possible unique contribution.

The Step 1 equation including the control variables, age and gender, did not account for a significant amount of variance for diabetes self-management, $F(2,62)=1.99, p=.145, R^{2}=.06$.

In the second step, diabetes-related distress and diabetes-related self-efficacy were entered into the model. The Step 2 equation accounted for a significant proportion of the variance in diabetes vself-management, $F(4,60)=4.29, p<.005, R^{2}=.222$. Moreover, diabetes- 
HEALTH LITERACY 28

related self-efficacy accounted for unique variance in frequency in diabetes self-management $(\beta$ $=.371, p<.005)$.

At Step 3, health literacy was added to the equation. Although this step did not increase the amount of variance explained in diabetes self-management, $[F \Delta(1,59)=.08, p=.780]$, the five-variable equation continued to reach significance $\left.F(5,59)=3.39, p=.009, R^{2}=.223\right)$. Selfefficacy continued to account for variance $(\beta=.37, p<.005)$, with higher diabetes-related selfefficacy associated with more frequent engagement in self-management activities (see Table 5).

The fifth and sixth hypotheses predicting that health literacy would mediate the relationship between diabetes-related distress and self-care activities or diabetes-related selfefficacy and self-care activities was examined. Using Baron and Kenny's (1986) criteria, neither mediation analysis was able to be performed due to lack of correlation between all variables as presented in Table 4. However because ECB Knowledge was significantly and positively correlated with health literacy, as well as diabetes-related distress $(r=-.379, p=.002)$ and selfmanagement $(r=-.257, p=.04$; as seen in Table 4), the ECB Knowledge was then used as a mediator in place of the health literacy between distress and self-management. Nonetheless, a linear regression found that ECB Knowledge also was not related to diabetes self-management, $F$ $(2,62)=3.00, p=.057 ; \beta=-.197, p=.138$.

\section{Post-Hoc Analyses}

Given that ECB Knowledge is highly correlated with health literacy, suggesting that they may be tapping into similar constructs; and age, ECB Knowledge, and self-management were all positively associated (see Table 4); a series of linear regressions, according to Baron and Kenny (1986), were conducted to determine whether ECB knowledge mediated the relation between age and self-care activities. Specifically, if older age is associated with higher ECB Knowledge, then 
higher ECB Knowledge will be related to better diabetes self-management. The first regression examined whether age was related to ECB Knowledge. It was found that age was significantly and positively associated with ECB Knowledge, $F(1,63)=10.06, p<.002 ; \beta=.371, p=.002$. The second regression examined whether ECB Knowledge was related to self-management. The analysis revealed that ECB Knowledge was significantly and positively associated with self-care activities, $F(1,63)=4.47, p=.038 ; \beta=-.257, p=.038$. The third regression examined whether age was related to self-management. The regression revealed that age was significantly and negatively related to self-management, $F(1,63)=4.04, p=.049 ; \beta=-.246, p=.05$. The final linear regression was conducted to determine whether ECB Knowledge mediated the relation between age and self-management. Analyses revealed that ECB Knowledge was found to be a possible mediator between the relation of age and diabetes self-management, $F(2,62)=3.16, p$ $=.05 ; \beta=-.193$. However a Sobel test revealed that ECB Knowledge did not mediate the relation between age and diabetes self-management, $z=-1.75, p=.08$.

Additionally, since being overweight or obese has been linked to increased risk for developing T2D as well as poorer glycemic control and given that the mean BMI of the current sample indicated obesity, that the relations between BMI and study variables of interest were examined. Correlations revealed that BMI was negatively associated with diabetes-related selfefficacy $(r=-.347, p<.05)$, health literacy $(r=.395, p<.05)$, ECB Knowledge $(r=.447, p=$ $.001)$, ECB Reasoning $(r=.398, p<.05)$, diabetes knowledge $(r=.350, p<.05)$ and selfmanagement $(r=-.406, p<.005)$. Concerning specific diabetes self-management domains, only $\operatorname{diet}(r=-.443, p=.001)$ and exercise $(r=-.462, p<.001)$ were found to be significantly associated with BMI, not the blood-glucose testing and foot care subscales. 
Given that the current sample on average had a BMI indicating obesity and that higher obesity was associated with lower diabetes-related self-efficacy and low diabetes selfmanagement, a series of regressions were conducted to examine whether higher diabetes-related self-efficacy could mediate the relation between high BMI and low diabetes self-management. The first regression examined the association between BMI and diabetes self-management. BMI was found to be significantly and negatively related to self-care activities, $F(1,51)=10.04 ; \beta=$ $-.406, p=.003$. The second regression examined the relationship between BMI and diabetesrelated self-efficacy. BMI was significantly and negatively related to diabetes self-efficacy, $F(1$, $51)=6.96 ; \beta=-.347, p=.011$. The third regression examined the association between diabetes self-efficacy and self-care activities. Diabetes-related self-efficacy was found to be significantly and positively related to self-care activities, $F(1,63)=7.94 ; \beta=.334, p=.006$. Finally, a fourth regression was conducted to determine if diabetes-related self-efficacy reduced the association between BMI and diabetes self-management. In the first step BMI was entered and in the second step diabetes-related self-efficacy was entered. In the final model, though the model was significant, the association between BMI and self-management was no longer significant, $F$ (2, $50)=18.97, p<.001 ; \beta=-.215, p=.065$. Though approaching significance, an insignificant Sobel test indicated that the association between BMI and self-management was mediated by diabetes-related self-efficacy was added to the model, $z=-1.92, S E=0.012, p=.054$ (Figure 2 presents the mediation model). 
HEALTH LITERACY 31

\section{Discussion}

The purpose of the current study was to determine the extent that health literacy, diabetes-related distress, and diabetes self-efficacy contributed to self-care activities in middleaged and older adults with type 2 diabetes. The following discussion will (a) outline the results of the hypotheses, (b) summarize the exploratory question results (c) review post hoc findings, (d) discuss overall study limitations, and (e) provide an overall study conclusion.

Age and Health Literacy. Unlike much of the current literature (Gazmararian et al., 1999; Kim, 2009; Kim, Love, Quistberg \& Shea, 2004; Schillinger et al., 2002), age was not found to be negatively associated with health literacy, but instead was moderately and positively associated, suggesting that older age is related to higher health literacy. Studies generally used a large range of ages or participants 18 years and older or limited age ranges with participants either being grouped as young adults or older adults (e.g., Gazmararian et al., 1999). Thus the current study may have different results due to focusing on mid- to late-life, in which there may be no substantial cognitive differences in a sample of adults aged 40-66.

Factors Influencing T2D Self-Management. Diabetes-related self-efficacy was found to be positively and moderately related to self-management of diabetes. This suggests that higher diabetes-related self-efficacy may play a constructive role in diabetes self-management. Additionally, regressions demonstrated that diabetes-related self-efficacy was a unique contributor to diabetes self-management, as opposed to diabetes-related distress and health literacy. The current finding corresponds with the literature that diabetes-related self-efficacy can be a predictor of engagement in self-care activities, with higher self-efficacy being linked to better self-management and lower self-efficacy being related to poorer self-management (e.g., 
HEALTH LITERACY 32

Sarkar, Fisher, \& Schillinger, 2006; Xu, Toobert, Savage, Pan, \& Whitmer, 2008). However, not all domains of self-management were found to be related to diabetes-related self-efficacy. Diet, exercise, and blood-glucose testing were found to be moderately and positively related to diabetes-related self-efficacy; but foot care was not found to be related to self-efficacy. This suggests that higher diabetes-related self-efficacy may be more important for some aspects of self-management but not all. Particularly those that may require more planning and decision making to implement (e.g., exercise).

Higher diabetes-related distress was not found to be related to less engagement in selfmanagement. Given that measures of diabetes-related distress and other measures of negative affect have been well linked to poorer management of T2D (e.g., Katon, 2008; Lin et al., 2004), the difference in findings may be due to the current sample. Firstly, the majority of the current sample reported having no current problems $(80 \%)$ with their diabetes, most also reported relatively healthy $\mathrm{HbAlc}$ values from their last test (values between 5.7\% and 7.0\%), and the majority reported they health status as fair $(23.1 \%)$, good $(46.2 \%)$ or very good $(20 \%)$. This indicates that the current sample may not have perceive any particular problems in dealing with their diabetes, resulting in relatively low scores that are not related to diabetes self-management.

Lastly, health literacy was not found to be related to diabetes self-management. It is unclear about the reasoning for the lack of association between health literacy and diabetes selfmanagement. The sample had relatively high health literacy scores on average suggesting having the skill to interpret and use health information. However, having the ability to use health information to inform decisions may not translate into application of those skills to diabetesspecific decisions and diabetes self-management. Research has shown that knowledge and awareness does not always result in engagement in health behaviors (Bettinghaus, 1986). Lastly, 
given the mediocre psychometrics of the Newest Vital Sign and other commonly used measures of health literacy, there may be issues of validity, reliability, or generalizability to age specific.

Gender and Health Literacy. The current study found differences between males and females, with females having higher health literacy. This fits with the current literature, in that there have been mixed findings with males and females being found to have higher health literacy or no differences being found (e.g., Kim, 2009; Schillinger et al., 2002). However, gender differences have been found in health information-seeking behavior, with women engaging in more health information-seeking behaviors (Weaver, Mays, Weaver, Hopkins, Eroğlu, \& Bernhardt, 2010). This suggests that women may be more health literacy saavy due to their more frequent interaction with healthcare-related materials.

Length of Diagnosis and Diabetes Self-Management. No significant differences were found in engagement in self-care activities for those who had been diagnosed with T2D for less than 5 years and those who had been diagnosed for 5 years or more. There is no consistent findings with many finding no differences (e.g., Polonsky, Fisher, Guzman, Philis-Tsimikas, \& Edelman, 2010) and others finding that those who have had diabetes longer to be less adherent in some aspects, such as self-monitoring of blood-glucose (Karter, Ferrara, Darbinian, Ackerson, \& Selby, 2000). Thus, length of diagnosis may not be related to diabetes self-management except for certain regimens of care.

\section{Relations Among the Newest Vital Sign, ECB Knowledge and Reasoning Tests, and} Diabetes Knowledge Test. The finding in the present study that the NVS, ECB test items (i.e., those related to medication use, health-related financial management, and food preparation and nutrition), and DKT were all highly correlated suggests that health-related knowledge and ability to apply that knowledge may not need be content specific. Given that research has found that 
those with lower health literacy also tend to have lower disease-specific knowledge, health literacy may play a large role in self-care activities through knowledge attainment (Gazmararian, Williams, Peel, \& Baker, 2003; Macabasco-O’Connell et al., 2011; Paasche-Orlow \& Wolf, 2007). Specifically, this suggests that lower health literacy may impede learning and utilizing information specific to their disease. Additionally, the close association between the health literacy and ECB Knowledge and Inductive Reasoning Tests may suggest health literacy may be measure of cognition. Particularly, given that the current study used only healthcare-related items from the ECB Knowledge and Inductive Reasoning Tests, application and interpretation of the health information maybe a cognitive task (e.g., problem-solving) as opposed to solely a literacy task (i.e., reading and understanding written information).

Age. The current study found a negative association between age and diabetes selfmanagement. Specifically, older age was found to be related to engagement in less diabetes selfmanagement. Comorbidities may make self-management more difficult due to physical limitations impeding exercise or due to the complexity of adequately managing multiple diseases (Spollett, 2006). Lastly, age-related cognitive impairment may hamper dietary planning and scheduling of regular engagement exercise to successfully management blood glucose.

BMI. For the present study, higher BMI was found to be moderately related to lower diabetes-related self-efficacy,higher health literacy, higher ECB Knowledge and Reasoning, higher diabetes knowledge, and less diabetes self-management—specifically diet and exercise. Additionally, it was found that diabetes-related self-efficacy mediated the relation between BMI and diabetes self-management. This suggests that those with a higher BMI may have a sense of failure to meet recommended standards due to their weight and thus can result in poorer selfmanagement (Sacco et al., 2007). Specifically, such perceptions may lower their self-efficacy to 
adequately control their diabetes, which may result in less motivation to engage in self-care activities (Bandura, 1982; 2005). Specifically, perceived past failures to maintain a healthy diet or exercise regimen may result in perceived lower ability to be able to perform such tasks successfully any time in the future. Conversely, lower diabetes-related self-efficacy may lead to less diabetes self-management and in turn results in higher BMI. The relation between health literacy and its comparative measures and BMI is unclear, given that it has been demonstrated that higher BMI is associated with lower cognitive scores (i.e., specifically memory, executive functioning, perceptual speed, verbal abilities, and spatial abilities) and declines in cognition across the life course (Sabia et al., 2008; Hassing, Dahl, Pedersen, \& Johansson, 2010). It may be that a third variable is involved in this relation; thus, further study is warranted to clarify the association.

\section{Limitations}

There are several limitations to take into consideration with regards to this study. Firstly, all items were self-report, thus data regarding diabetes diagnosis may have been inaccurate (e.g., had Type 1 Diabetes, not T2D) as well as the date of diagnosis and frequency of engagement in diabetes self-care activities. This may be due to memory, misunderstanding of types of diabetes, or social desirability concerning frequency of engaging in self-care activities. Additionally, due to the lack of mixed methods, there may have been issues of monomethod biases that may have caused problems of shared variance and may result in inflated effects.

Additionally, the sample may not be representative of all middle-aged and older adults with T2D. Firstly, the lack of racial and ethnic diversity limits the ability to generalize to those who are not Caucasian. Secondly, recruitment of participants online as compared to in clinic may have reduced generalizability. Specifically, a sample recruited through attendance at a medical 
clinic may be particularly attentive to their diabetes self-management and represent a unique population. Thus, diabetes self-management may have been different in the current study's results if in-clinic participants were included. Additionally, although it has been found that a sizeable portion of middle aged (78\%) and older adults (48\%) use the internet, on a daily basis (79\% and 60\% respectively; Keenan, 2009), this sample may represent a highly educated group (66.2\% had at least some college education) which may limit generalizability to those with less than a high school education. Thus, results may not generalize to those with education less than high school or those with less frequent interaction with the internet. Lastly, measure ranges may have been constricted by the homogeneity of the sample and the samples' high education status.

\section{Overall Conclusions}

Despite limitations, this study demonstrated that diabetes self-efficacy may be important in when considering diabetes self-management more so than health literacy or diabetes-related distress. However, there may be other variables, including age and BMI, that may play an important role in successful diabetes self-management. Future studies and interventions targeted at increasing diabetes self-management among middle-aged and older adults with T2D would benefit from a more comprehensive, but general health literacy measure. Additionally, older adults, individuals who are overweight or obese, and individuals with particularly low diabetes self-efficacy should have individualized interventions to identify perceived and actual barriers to self-care activities. Additionally, large longitudinal studies will inform how interventions aimed to lower BMI or increase diabetes-related self-efficacy may affect adequate self-management of T2D. 


\section{References}

A.D.A.M. Medical Encyclopedia. 2005. HbA1c. Retrieved from: http://www.nlm.nih.gov/medlineplus/ency/article/003247.htm

Allaire, J. C. \& Marsiske, M. (1999). Everyday cognition: Age and intellectual ability correlates. Psychology and Aging, 14 (4), 627-644.

Anderson, R. M., Fitzgerald, J. T., Gruppen, L. D., Funnell, M. M., \& Oh, M. S. (2003). The diabetes empowerment scale-short form (des-sf). Diabetes Care, 26 (5), 1641-1642.

Anderson, R. J., Freedland,K. E., Clouse, R. E., \& Lustman, P. J. (2001). The prevalence of comorbid depression in adults with diabetes. Diabetes Care, 24 (6), 1069-1078.

Anderson, R. M., Funnell, M. M., Fitzgerald, J. T., \& Marrero, D. G. (2000). The diabetes empowerment scale: A measure of psychosocial self-efficacy. Diabetes Care, 23 (6), 739-743.

Baker, D. W., Williams, M. V., Parker, R. M., Gazmararian, J. A., \& Nurss, J. (1999). Development of a brief test to measure functional health literacy. Patient Education and Counseling, 38(1), 33-42.

Bandura, A. (1982). Self-efficacy mechanism in human agency. American Psychologist, 37 (2), $122-147$.

Bettinghaus, E. P. (1986). Health promotion and the knowledge-attitude-behavior continuum. Preventive Medicine, 15 (5), 475-491.

Biggs, M. L., Mukamal, K. J., Luchsinger, J. A., Ix, J. H., Carnethon, M. R., Newman, A. B.,... Siscovick, D. S. (2010). Association between adiposity in midlife and older age and risk of diabetes in older adults. Journal of the American Medical Association, 303 (24), 25042512. 
HEALTH LITERACY 38

Bosworth, H. B. (2010). Challenges and strategies to improve patient health literacy and competencies. Patient Intelligence, 2, 19-25.

Centers for Disease Control and Prevention (CDC). (2011). About bmi for adults. Retrieved from http://www.cdc.gov/healthyweight/assessing/bmi/adult_BMI/index.html

Centers for Disease Control and Prevention (CDC). (2011). National diabetes fact sheet: National estimates and general information of diabetes and prediabetes in the united states. Atlanta, GA; U.S. Department of Health and Human Services.

Cherrington, A., Wallston, K. A., \& Rothman, R. L. (2010). Exploring the relationship between diabetes self-efficacy, depressive symptoms, and glycemic control among men and women with type 2 diabetes. Journal of Behavioral Medicine, 33 (1), 81-89.

Ciechanowski, P. S., Katon, W. J., \& Russo, J. E. (2000). Depression and diabetes: Impact of depressive symptoms on adherence, function, and costs. Archives of Internal Medicine, 160 (21), 3278-3285.

Delahanty, L. M., Grant, R. W., Wittenberg, E., Bosch, J. L., Wexler, D. J., Cagliero, E., \& Meigs, J. B. (2007). Association of diabetes-related emotional distress with diabetes treatment in primary care patients with type 2 diabetes. Diabetic Medicine, 24 (1), 48-54.

Dillman, D. A. (2000). Constructing the questionnaire. Mail and internet surveys: The tailored design method. New York: Wiley.

Federman, A. D., Sano, M., Wolf, M. S., Siu, A. L., \& Halm, E. A. (2009). Health literacy and cognitive performance in older adults. Journal of the American Geriatrics Society, 57 (8), $1475-1480$.

Fitzgerald, J. T., Funnell, M. M., Hess, G. E., Barr, P. A., Anderson, R. M., Hiss, R. G., \& Davis, W. K. (1998). The reliability and validity of a brief diabetes knowledge test. Diabetes 
HEALTH LITERACY 39

Care, 21(5), 706-710.

Gazmararian, J. A., Baker, D. W., Williams, M. V., Parker, R. M., Scott, T. L., Green, D. C.,... Koplan, J. P. (1999). Health literacy among medicare enrollees in a managed care organization. Journal of the American Medical Association, 281 (3), 545-551.

Gazmararian, J. A., Williams, M. V., Peel, J., \& Baker, D.W. (2003). Health literacy and knowledge of chronic disease. Patient Education and Counseling, 51 (6), 267-275.

Gecas, V. (1989). The social psychology of self-efficacy. Annual Review of Sociology, 15, 291316.

Gonzalez, J. S., Safren, S. A., Cagliero, E., Wexler, D. J., Delahanty, L., Wittenberg, E.,...Grant, R. W. (2007). Depression, self-care, and medication adherence in type 2 diabetes. Diabetes Care, 30 (9), 2222-2227.

Hassing, L. B., Dahl, A. R., Pedersen, N. L., \& Johansson, B. (2010). Overweight in midlife is related to lower cognitive function 30 years later: A prospective study with longitudinal assessments. Dementia and Geriatric Cognitive Disorders, 29 (6), 543-552.

Johnson, K., \& Weiss, B. D. (2008). How long does it take to assess literacy skills in clinical practice? Journal of the American Board of Family Medicine, 21(3), 211-214.

Karter, A. J., Ferrara, A., Darbinian, J. A., Ackerson, L. M., \& Selby, J. V. (2000). Selfmonitoring of blood glucose: Language and financial barriers in a managed care population with diabetes. Diabetes Care, 23(4), 477-483.

Katon, W. J. (2008). The comorbidity of diabetes mellitus and depression. The American Journal of Medicine, 121 (11 S2), S8-S15.

Keenan, T. A. (2009). Internet use among midlife and older adults: An aarp bulletin poll. Retrieved from http://assets.aarp.org/rgcenter/general/bulletin_internet_09.pdf. 
HEALTH LITERACY 40

Kim, S. H. (2009). Health literacy and functional health status in korean older adults. Journal of Clinical Nursing, 18(16), 2337-2343.

Kim, S., Love, F., Quistberg, D. A., \& Shea, J. A. (2004). Association of health literacy with self-management behavior in patients with diabetes. Diabetes Care, 27 (12), 2980-2982.

King, D. K., Glasgow, R. E., Toobert, D. J., Strycker, L. A., Estabrooks, P. A., Osuna, D., \& Faber, A. J. (2010). Self-efficacy, problem-solving, and social-environmental support are associated with diabetes self-management behaviors. Diabetes Care, 33 (4), 751-753.

Kutner, M., Greenberg, E., Jin,Y., and Paulsen, C. (2006). The health literacy of america's adults: Results from the 2003 national assessment of adult literacy (NCES 2006-483).U. S.Department of Education.Washington, DC: National Center for Education Statistics.

Lin, E. H. B., Katon, W., Von Korff, M., Rutter, C., Simon, G. E., Oliver, M.,...Young, B. (2004). Relationship of depression and diabetes self-care, medication adherence, and preventive care. Diabetes Care, 27 (9), 2154-2160.

Lustman, P. J., Penckofer, S. M., \& Clouse, R. E. (2007). Recent advances in understanding depression in adults with diabetes. Current Diabetes Reports, 7 (2), 114-122.

Macabasco- O’Connell, A., DeWalt, D. A., Broucksou, K. A., Hawk, V., Baker, D. W., Schillinger, D.,... Pignone, M. (2011). Relationship between literacy, knowledge, selfcare behaviors, and heart failure-related quality of life among patients with heart failure. Journal of General Internal Medicine, 269 (9), 979-986.

Nakahara, R., Yoshiuchi, K., Kumano, H., Hara, Y., Suematsu, H., \& Kuboki, T. (2006). Prospective study on influence of psychosocial factors on glycemic control in japanese patients with type 2 diabetes. Psychosomatic, 47 (3), 240-246. 
HEALTH LITERACY 41

Nam, S., Chesla, C., Stotts, N. A., Kroon, L. \& Janson, S. L. (2010). Factors associated with psychological insulin resistance in individuals with type 2 diabetes. Diabetes Care, 33 (8), 1747-1749.

National Diabetes Education Program (NDEP). (2009). Guiding principles for diabetes care: For health care professionals (NIH Publication No.09-4343). Retrieved from http://ndep.nih.gov/media/GuidPrin_HC_Eng.pdf

National Diabetes Information Clearinghouse (NDIC). (2008). National diabetes statistics, 2007 (NIH Publication No. 08-3892). Retrieved from http://diabetes.niddk.nih.gov/dm/pubs/statistics/DM_Statistics.pdf

National Diabetes Information Clearinghouse (NDIC).(2008). Diagnosis of diabetes (NIH Publication No. 09-4642). Retrieved from http://diabetes.niddk.nih.gov/dm/pubs/diagnosis/diagnosis.pdf

National Diabetes Information Clearinghouse (NDIC).(2008). Diabetes overview (NIH Publication No.09-03873). Retrieved from http://diabetes.niddk.nih.gov/dm/pubs/overview/DiabetesOverview.pdf

Nutbeam, D. (2008). The evolving concept of health literacy. Social Science and Medicine, 67 (12), 2072-2078.

Osborn, C. Y., Cavanaugh, K., Wallston, K. A., White, R. O., Rothman, R. L. (2009). Diabetes numeracy: An overlooked factor in understanding racial disparities in glycemic control. Diabetes Care, 32 (9), 1614-1619.

Paasche-Orlow, M. K. \& Wolf, M. S. (2007). The causal pathways linking health literacy to health outcomes. American Journal of Health Behavior ,31 (S1), S19-S26. 
Park, H., Hong, Y., Lee, H., Ha, E., \& Sung, Y. (2004). Individuals with type 2 diabetes and depressive symptoms exhibited lower adherence with self-care. Journal of Clinical Epidemiology, 57 (9), 978-984.

Patel, P. J., Steinberg, J., Goveas, R., Pedireddy, S., Saad, S., Rachmale, R.,..\&\& Cardozo, L. (2011). Testing the utility of the newest vital sign (nvs) assessment tool in older africanamerican patients. Patient Education and Counseling, 85(3), 505-507.

Polonsky, W. H., Anderson, B. J., Lohrer, P. A., Welch, G. (1995). Assessment of diabetesrelated distress. Diabetes Care, 18(6), 754-760.

Polonsky, W. H., Fisher, L., Guzman, S., Sieber, W. J., Philis-Tsimikas, A., \& Edelman, S. V. (2010). Are patients' initial experiences at the diagnosis of type 2 diabetes associated with attitudes and self-management over time? The Diabetes Educator, 36 (5), 828-834.

Powell, C. K., Hill, E. G., \& Clancy, D. E. (2007). The relationship between health literacy and diabetes knowledge and readiness to take health actions. The Diabetes Educator, 33 (1), $144-151$.

Riddle, M. C. \& Genuth, S. (2010). Type 2 diabetes mellitus. In DC Dale, DD Federman (EDs.), ACP Medicine (pp.1-18).DOI:10.2310/7900.1157.

Rudd, R. E. (2007). Health literacy skills of u.s. adults. American Journal of Health Behavior, 32 (S1), S8-S18.

Sabia, S., Kivimaki, M., Shipley, M. J., Marmot, M. G., and Singh-Manoux, A. (2009). Body mass index over the adult life course and cognition in late midlife: The whitehall II cohort study. American Journal of Clinical Nutrition, 89(2), 601-607.

Sacco,W. P., Wells, K. J., Friedman, A., Matthew, R.., Perez, S., \&Vaughan, C. A. (2007). Adherence, body mass index, and depression in adults with type 2 diabetes: The 
HEALTH LITERACY 43

meditational role of diabetes symptoms and self-efficacy. Health Psychology, 26, 693700.

Sakar, U., Fisher, L., \& Schillinger, D. (2006). Is self-efficacy associated with diabetes selfmanagement across race/ethnicity and health literacy? Diabetes Care,29 (4), 823-829.

Schillinger, D., Grumbach, K., Piette, J., Wang, F., Osmond, D., Daher, C., Palacios, J., Sullivan, G. B., \& Bindman, A. B. (2002).Association of health literacy with diabetes outcomes. Journal of the American Medicine Association, 288 (4), 475-482.

Snoek,F. J., Pouwer, F., Welch, G. W., \& Polonsky, W. H. (2000). Diabetes-related emotional distress in dutch and u. s. diabetic patients: Cross-cultural validity of the problem areas in diabetes scale. Diabetes Care, 23 (9), 1305-1309.

Sousa, V. D, Zauszniewski, J. A., Musil, C. M., Price Lea, P. J., \& Davis, S. A. (2005). Relationships among self-care agency, self-efficacy, self-care, and glycemic control. Research and Theory for Nursing Practice: An International Journal, 19 (3), 217-230.

Spollett, G. R. (2006). Type 2 diabetes across the life span. In C. Mensing (Ed.), Art and science of diabetes self-management education: A desk reference for healthcare professionals (pp. 215-231). Retrieved from http://www.diabeteseducator.org/_resources/pdf/dr_chapter10.pdf

Tang, Y. H., Pang, S. M. C., Chan, M. F., Yeung, G. S. P., \& Yeung, V. T. F. (2007). Health literacy, complication awareness, and diabetic control in patients with type 2 diabetes mellitus. Journal of Advanced Nursing, 62(1), 74-83.

Toobert, D. J., Hampson, S. E., \& Glasgow, R. E. (2000). The summary of diabetes self-care activities measure: Results from 7 studies and a revised scale. Diabetes Care, 23(7), 943950. 
Weaver, J. B., Mays, D., Weaver, S. S., Hopkins, G. L., Eroğlu, D., \& Bernhardt, J. M. (2010). Health information-seeking behaviors, health indicators, and health risks. American Journal of Public Health, 100 (8), 1520-1525.

Weiss, B. D., Mays, M. Z., Martz, W., Castro, K. M., DeWalt, D. A., Pignone, M. P.,... Hale, F. A. (2005). Quick assessment of literacy in primary care: The newest vital sign. Annals of Family Medicine, 3(6), 514-522.

Welch, G. W., Jacobson, A. M., \& Polonsky, W. H. (1997). The problem areas in diabetes scale: An evaluation of its clinical utility. Diabetes Care, 20 (5), 760-766.

Welch, G., Weinger, K., Anderson, B., \& Polonsky, W. H. (2003). Diabetic Medicine, 20 (1), 69-72.

World Health Organization (WHO). (1995). The world health report, 1995: Bridging the gap. Retrieved from http://www.who.int/whr/1995/en/index.html

Xu, Y., Toobert, D., Savage, C., Pan, W., \&Whitmer, K. (2008). Factors influencing diabetes self-management in chinese people with type 2 diabetes. Research in Nursing and Health, 31 (6), 613-625. 
Tables

Table 1. Additional Descriptive Information $(N=65)$

\begin{tabular}{|c|c|c|c|c|}
\hline Variable & & $\mathbf{n}$ & $\%$ & Missing (n) \\
\hline \multirow[t]{3}{*}{ Gender } & & & & - \\
\hline & Male & 32 & 49.2 & \\
\hline & Female & 33 & 50.8 & \\
\hline \multirow[t]{6}{*}{ Race } & & & & 1 \\
\hline & Caucasian & 55 & 84.6 & \\
\hline & African American & 6 & 9.2 & \\
\hline & Native Hawaiian/Other Pacific & & & \\
\hline & Islander & 1 & 1.5 & \\
\hline & Other (Hispanic) & 2 & 3.1 & \\
\hline \multirow[t]{5}{*}{ Marital Status } & & & & - \\
\hline & Married & 50 & 76.9 & \\
\hline & Widowed & 4 & 6.2 & \\
\hline & Divorced & 7 & 10.8 & \\
\hline & Single, Never Married & 4 & 6.2 & \\
\hline \multicolumn{2}{|c|}{ Living Arrangement } & & & - \\
\hline & Alone & 9 & 13.8 & \\
\hline & With Spouse & 49 & 75.4 & \\
\hline & With Others & 7 & 10.8 & \\
\hline \multirow[t]{6}{*}{ Education } & & & & 6 \\
\hline & Less than High School & 1 & 1.5 & \\
\hline & High School & 15 & 23.1 & \\
\hline & Some College & 15 & 23.1 & \\
\hline & College & 18 & 27.7 & \\
\hline & Graduate/Professional & 10 & 15.4 & \\
\hline \multicolumn{2}{|c|}{ Difficulty Paying Bills } & & & 1 \\
\hline & None & 13 & 20.0 & \\
\hline & A Little & 18 & 27.7 & \\
\hline & Some & 22 & 33.8 & \\
\hline & A Great Deal & 11 & 16.9 & \\
\hline \multicolumn{2}{|c|}{ Current Work Status } & & & 1 \\
\hline & Full-Time & 41 & 63.1 & \\
\hline & Part-Time & 8 & 12.3 & \\
\hline & Retired & 6 & 9.2 & \\
\hline & Unemployed/Homemaker & 7 & 10.8 & \\
\hline & Other & 2 & 3.1 & \\
\hline \multirow[t]{3}{*}{ Recruitment } & & & & - \\
\hline & StudyResponse & 43 & 66.2 & \\
\hline & Mechanical Turk & 22 & 33.8 & \\
\hline
\end{tabular}


Table 2. Health Specific Information

\begin{tabular}{|c|c|c|c|c|}
\hline Variable & & $\mathbf{n}$ & $\%$ & Missing (n) \\
\hline \multicolumn{5}{|l|}{ Current Problems with } \\
\hline \multirow[t]{3}{*}{ Diabetes } & & & & - \\
\hline & Yes & 13 & 20.0 & \\
\hline & No & 52 & 80.0 & \\
\hline \multirow[t]{6}{*}{ Results of Last HbA1C Test } & & & & 1 \\
\hline & Less than $5.7 \%$ & 5 & 7.7 & \\
\hline & $5.7 \%-6.4 \%$ & 25 & 38.5 & \\
\hline & $6.5 \%-7.0 \%$ & 15 & 23.1 & \\
\hline & Greater than $7.0 \%$ & 3 & 4.6 & \\
\hline & I don't know & 16 & 24.6 & \\
\hline \multirow[t]{6}{*}{ General Health Status } & & & & 1 \\
\hline & Poor & 2 & 3.1 & \\
\hline & Fair & 15 & 23.1 & \\
\hline & Good & 30 & 46.2 & \\
\hline & Very Good & 13 & 20.0 & \\
\hline & Excellent & 4 & 6.2 & \\
\hline \multicolumn{2}{|c|}{ Health Problems Stand in the Way } & & & - \\
\hline & Not at all & 10 & 15.4 & \\
\hline & A Little & 47 & 72.3 & \\
\hline & A Great Deal & 8 & 12.3 & \\
\hline & & Mean & SD & $\begin{array}{l}\text { Missing } \\
\text { (n) }\end{array}$ \\
\hline \multirow{2}{*}{\multicolumn{2}{|c|}{$\begin{array}{l}\text { BMI* } \\
\text { Number of Medical }\end{array}$}} & 28.7 & 6.9 & 12 \\
\hline & & & & \\
\hline \multicolumn{2}{|l|}{ Conditions } & 2.2 & 1.6 & 8 \\
\hline
\end{tabular}

*Note: Participants were excluded if height, weight, or both were missing, making it impossible to calculate BMI. 
Table 3. Descriptives for Measures

\begin{tabular}{llcc}
\hline Variable & & Mean & SD \\
\hline Health Literacy & & 3.8 & 2.4 \\
Diabetes Self-Efficacy & & 4.2 & 0.5 \\
& $\begin{array}{l}\text { Managing Psychosocial } \\
\text { Aspects }\end{array}$ & 4.2 & 0.7 \\
& Assessing Dissatisfaction \& & 4.1 & 0.7 \\
& Readiness to Change & & \\
Diabetes Distress & Setting \& Achieving Goals & 4.1 & 0.8 \\
Self-Management & & 51.7 & 27.1 \\
(days) & & 4.1 & 1.3 \\
& Diet & 4.3 & 1.3 \\
& Exercise & 3.9 & 1.9 \\
& Blood-Glucose Testing & 4.9 & 2.4 \\
ECB Reasoning & Foot Care & 3.2 & 2.2 \\
ECB Knowledge & & 40.1 & 12.5 \\
Diabetes Knowledge & & 12.2 & 3.5 \\
& & 14.2 & 5.3 \\
\hline Health Literacy Level & & $\mathbf{n}$ & $\mathbf{\%}$ \\
& Inadequate & 19 & 29.2 \\
& Limited & 4 & 6.2 \\
& Adequate & 42 & 64.6 \\
\hline
\end{tabular}


Table 4. Correlations of Measures and Age

\begin{tabular}{llllllllll}
\hline & Variable & $\mathbf{1}$ & $\mathbf{2}$ & $\mathbf{3}$ & $\mathbf{4}$ & $\mathbf{5}$ & $\mathbf{6}$ & $\mathbf{7}$ & $\mathbf{8}$ \\
\hline $\mathbf{1}$ & Self-Care Activities & - & & & & & & & \\
$\mathbf{2}$ & Distress & .235 & - & & & & & \\
$\mathbf{3}$ & Health Literacy & -.197 & $-.297^{*}$ & - & & & & \\
$\mathbf{4}$ & Self-Efficacy & $.334^{* *}$ & -.146 & -.132 & - & & & \\
$\mathbf{5}$ & ECB Reasoning & -.181 & $-.41^{* *}$ & $.841^{* *}$ & -.151 & - & & \\
$\mathbf{6}$ & ECB Knowledge & $-.257^{*}$ & $-.379^{* *}$ & $.789^{* *}$ & .052 & $.838^{* *}$ & - & & \\
$\mathbf{7}$ & Diabetes Knowledge & -.168 & $-.407^{* *}$ & $.705^{* *}$ & -.160 & $.796^{* *}$ & $.710^{* *}$ & - & \\
$\mathbf{8}$ & Age & $-.246^{*}$ & $-.324^{* *}$ & $.345^{* *}$ & .003 & $.330^{* *}$ & $.371^{* *}$ & $.356 * *$ & - \\
\hline
\end{tabular}

Note: ${ }^{*} p<.05,{ }^{* *} p<.01$. 
Table 5. Linear Regression: Diabetes Self-management regressed onto Distress, Self-Efficacy, and Health Literacy

\begin{tabular}{lllll}
\hline & $\beta$ & $R^{2}$ & $F$ & $d f$ \\
\hline Step 1 & & & & \\
Age & & .06 & 1.99 & 2,62 \\
Gender & .004 & & & \\
Step 2 & & .222 & $4.29 *$ & 4,60 \\
Age & -.182 & & & \\
Gender & .049 & & & \\
Distress & .241 & & & \\
Self-Efficacy & $.371 *$ & & & \\
Step 3 & & .223 & $3.39 * *$ & 5,59 \\
Age & -.174 & & & \\
Gender & .056 & & & \\
Distress & .233 & & \\
Self-Efficacy & $.366^{*}$ \\
Health Literacy & -.036 & & \\
\hline Note: ${ }^{*} p<.05, * * p$ & $<.01 ;$ Final Model: Adjusted $R^{2}=.158, R^{2} \Delta=.001, F \Delta=.079, p=.78$.
\end{tabular}




\section{Figures}

Figure 1.Conceptual models to be tested include a) three proposed direst pathways (health literacy, distress, and self-efficacy) to diabetes self-management; and b) two proposed mediated pathways, in which health literacy mediates the relation between distress and self-management and the relation between self-efficacy and self-management of diabetes.

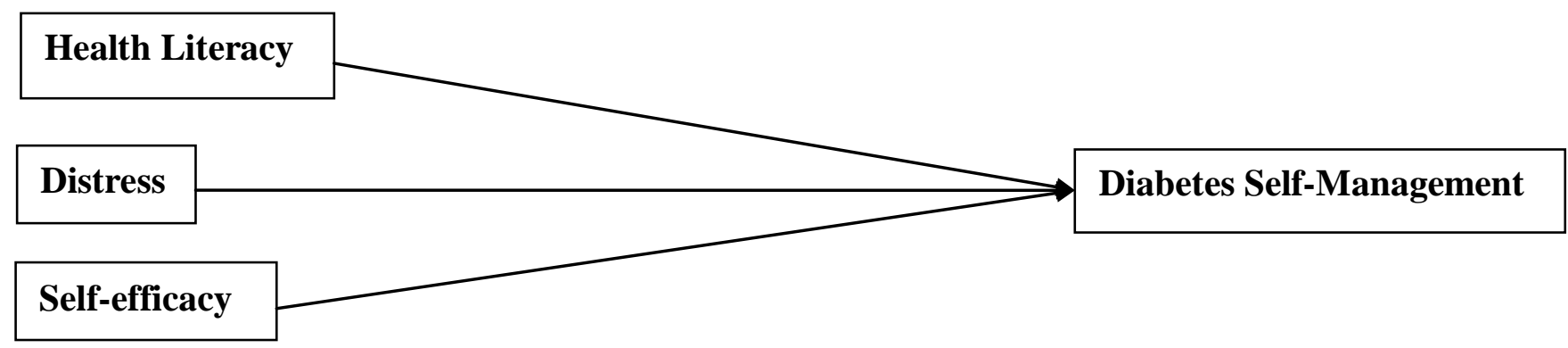

a) Direct Pathways

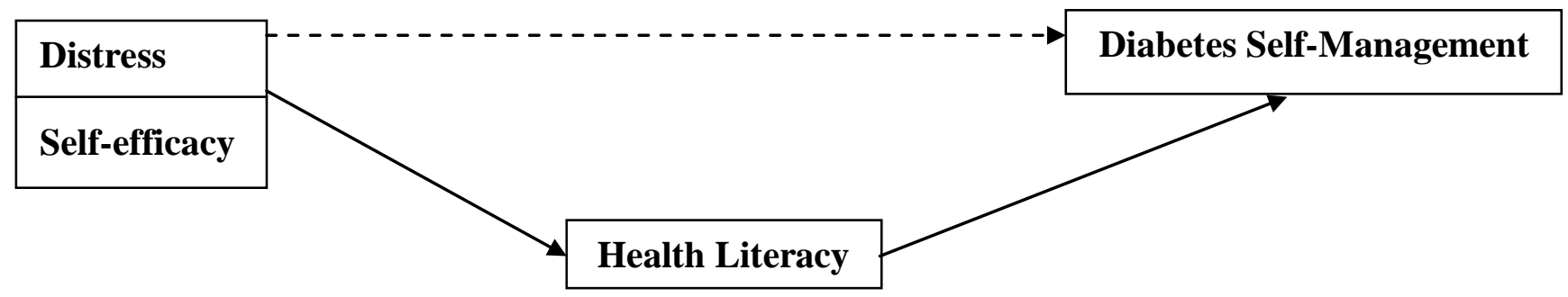

b) Mediated Pathways 
Figure 2. Mediation model of BMI, Diabetes Self-Efficacy, and Diabetes Self-Management.

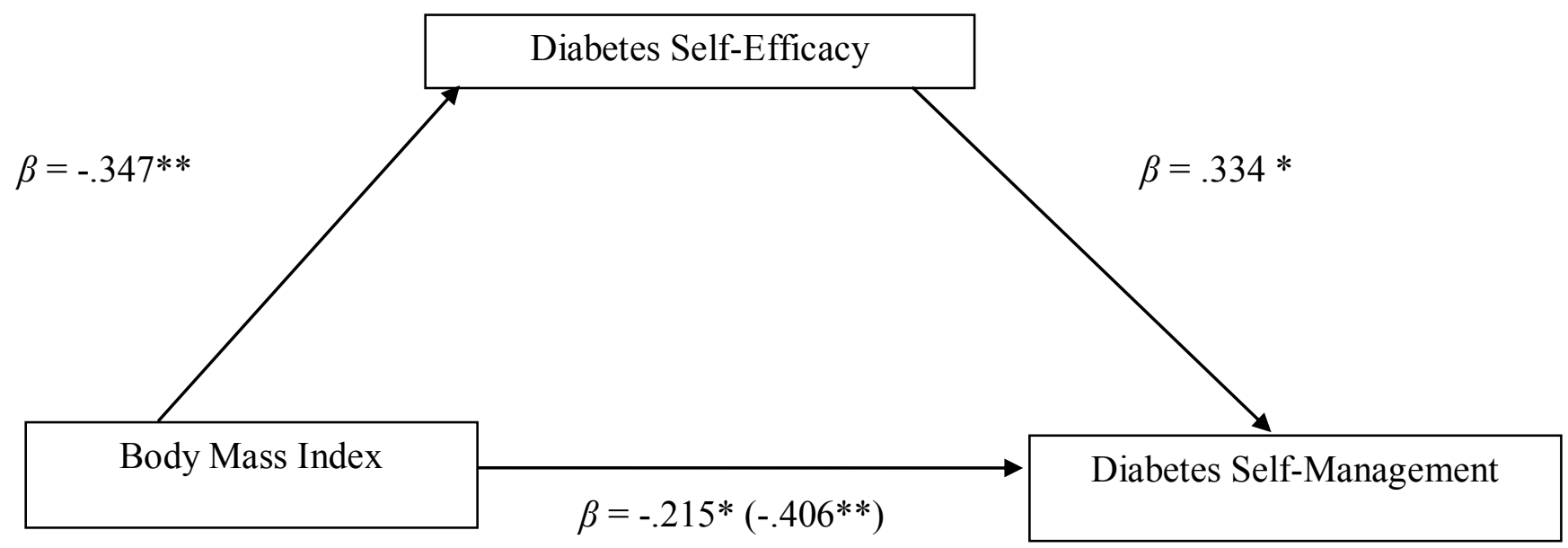

Note: ${ }^{*} p<.05,{ }^{*} p<<.01$. Sobel test $z=-1.92, p=.05$. 


\section{Appendix A}

\section{Tier 1: StudyResponse Recruitment Phase 1}

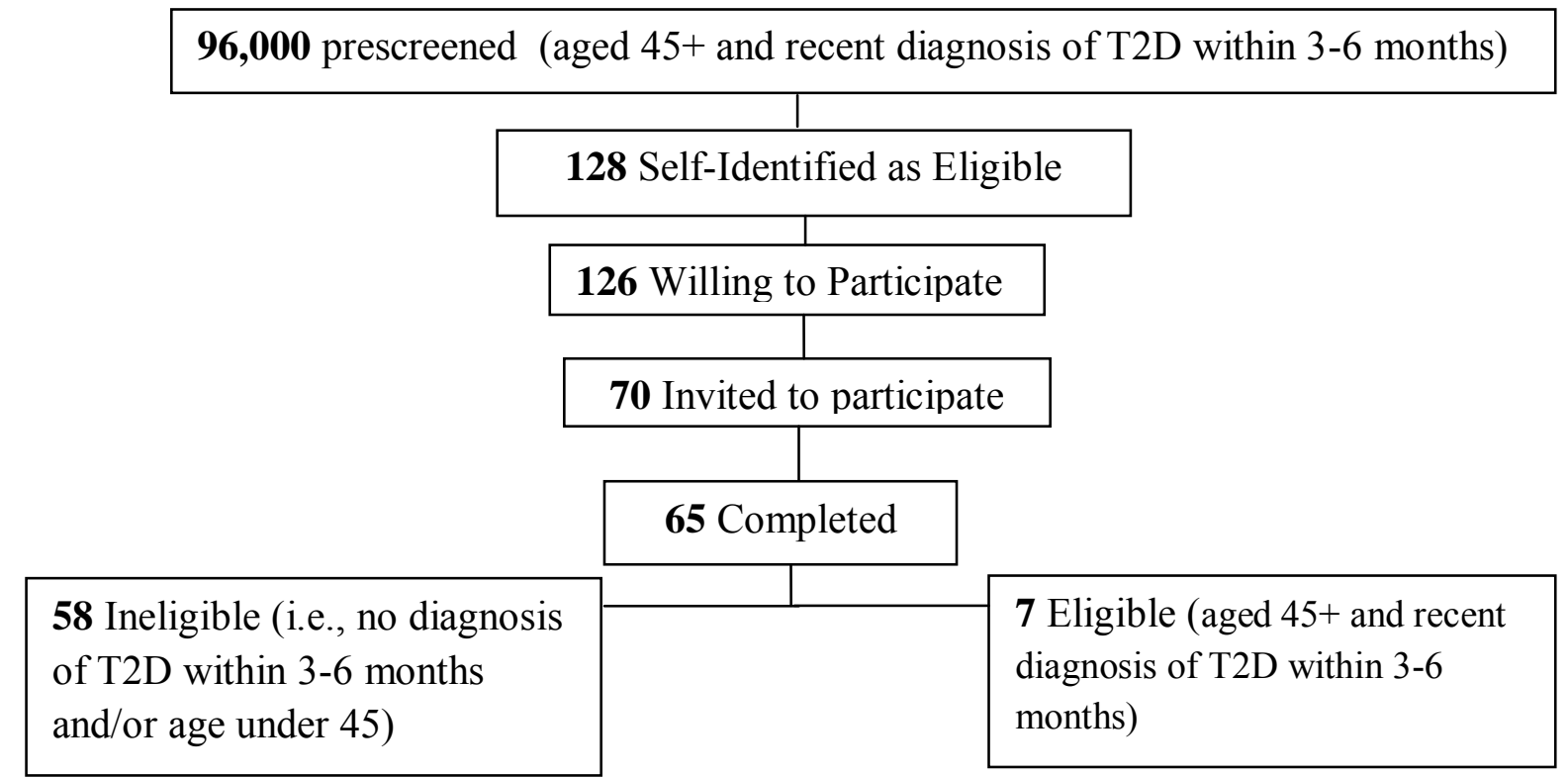

\section{StudyResponse Recruitment Phase 2}

55 Ineligible (i.e., no diagnosis of T2D within 3-6 months and/or age under 45)

Unknown Number

Invited to Participate

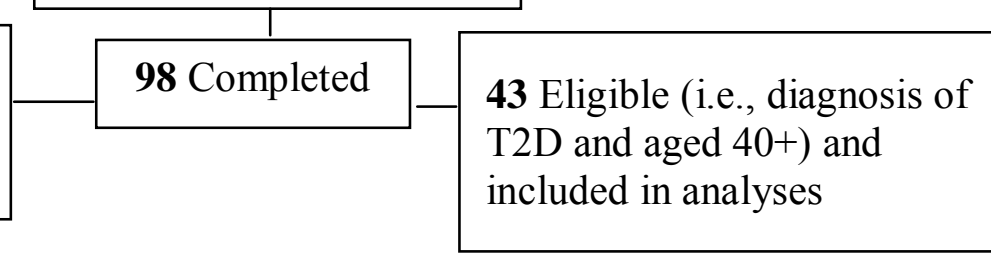

Tier 2: Mechanical Turk Outreach

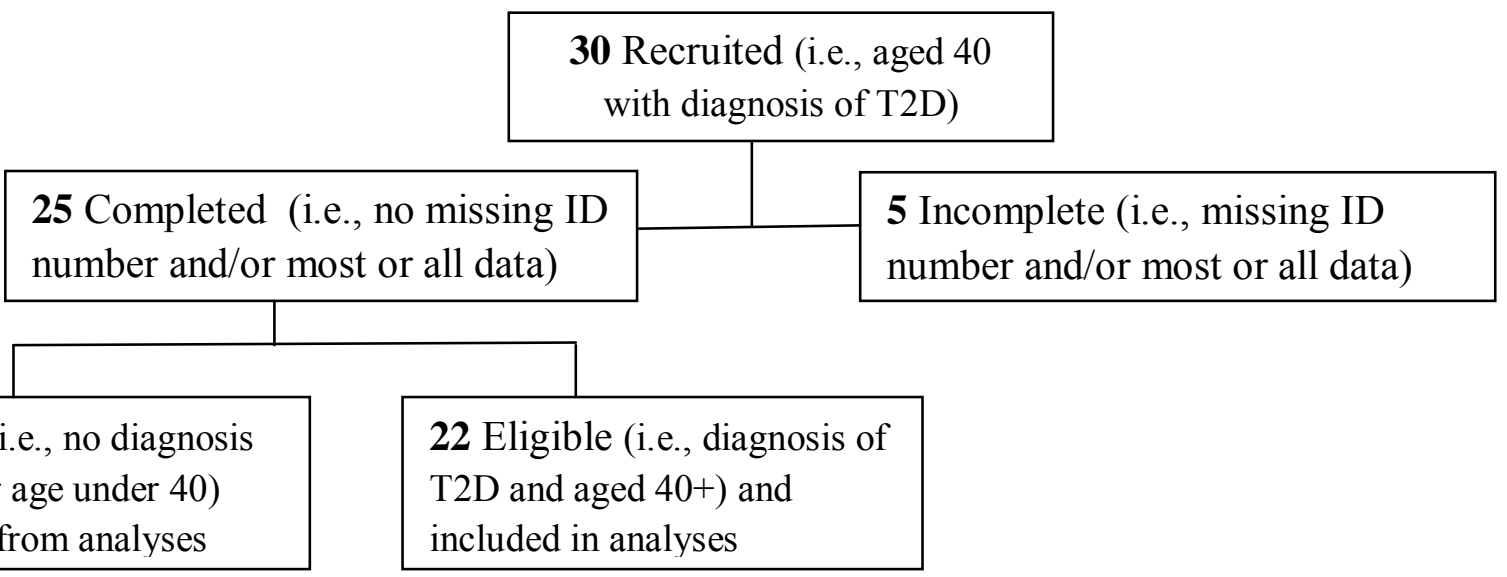

3 Ineligible (i.e., no diagnosis of T2D and/or age under 40) and excluded from analyses
22 Eligible (i.e., diagnosis of 40+) and ncluded in analyses 


\section{Appendix B}

\section{SDSCA}

The questions below ask about your diabetes self-care activities during the past seven days. If you were sick during the past seven days please think back to the last seven days when you were not sick.

\section{Diet Number of Days}

\begin{tabular}{|l|c|c|c|c|c|c|c|c|}
\hline $\begin{array}{l}\text { 1. On average, over the past } \\
\text { month, how many days per week } \\
\text { have you followed your eating } \\
\text { plan? }\end{array}$ & 0 & 1 & 2 & 3 & 4 & 5 & 6 & 7 \\
\hline $\begin{array}{l}\text { 2. On how many of the last seven } \\
\text { days did you eat five or more } \\
\text { servings of fruits and vegetables? }\end{array}$ & 0 & 1 & 2 & 3 & 4 & 5 & 6 & 7 \\
\hline $\begin{array}{l}\text { 3. On how many of the last seven } \\
\text { days did you eat high fat foods } \\
\text { such as red meat or full-fat dairy } \\
\text { products? }\end{array}$ & 0 & 1 & 2 & 3 & 4 & 5 & 6 & 7 \\
\hline $\begin{array}{l}\text { 4. On how many of the last seven } \\
\text { days did you space carbohydrates } \\
\text { evenly through the day? }\end{array}$ & 0 & 1 & 2 & 3 & 4 & 5 & 6 & 7 \\
\hline $\begin{array}{l}\text { 5. On how many of the last seven } \\
\text { days have you followed a } \\
\text { healthful eating plan? }\end{array}$ & 0 & 1 & 2 & 3 & 4 & 5 & 6 & 7 \\
\hline
\end{tabular}




\begin{tabular}{|l|l|l|l|l|l|l|l|l|}
\hline $\begin{array}{l}\text { 1. On how many of the last seven days did } \\
\text { you participate in at least 30 minutes of } \\
\text { physical activity? }\end{array}$ & 0 & 1 & 2 & 3 & 4 & 5 & 6 & 7 \\
\hline $\begin{array}{l}\text { 2. On how many of the last seven days did } \\
\text { you participate in a specific exercise } \\
\text { session (such as such swimming, walking, } \\
\text { biking) other than what you do around the } \\
\text { house or as part of your work? }\end{array}$ & 0 & 1 & 2 & 3 & 4 & 5 & 6 & 7 \\
\hline
\end{tabular}

Blood Sugar Testing

Number of Days

\begin{tabular}{|l|l|l|l|l|l|l|l|l|}
\hline $\begin{array}{l}\text { 1. On how many of the last seven days } \\
\text { did you test your blood sugar? }\end{array}$ & 0 & 1 & 2 & 3 & 4 & 5 & 6 & 7 \\
\hline $\begin{array}{l}\text { 2. On how many of the last seven days } \\
\text { did you test your blood sugar the number } \\
\text { of times recommended by your health } \\
\text { care provider? }\end{array}$ & 0 & 1 & 2 & 3 & 4 & 5 & 6 & 7 \\
\hline
\end{tabular}

Foot Care Number of days

\begin{tabular}{|l|c|c|c|c|c|c|c|c|}
\hline $\begin{array}{l}\text { 1. On how many of the last seven days } \\
\text { did you check your feet? }\end{array}$ & 0 & 1 & 2 & 3 & 4 & 5 & 6 & 7 \\
\hline $\begin{array}{l}\text { 2. On how many of the last seven days } \\
\text { did you inspect the inside of your shoes? }\end{array}$ & 0 & 1 & 2 & 3 & 4 & 5 & 6 & 7 \\
\hline
\end{tabular}




\section{Appendix C \\ DES-SF}

Circle the box that gives the best answer for you.

\section{In general, I believe that I:}

\begin{tabular}{|c|c|c|c|c|c|c|}
\hline & & $\begin{array}{l}\text { Strongly } \\
\text { Disagree }\end{array}$ & $\begin{array}{c}\text { Somewhat } \\
\text { Disagree }\end{array}$ & Neutral & $\begin{array}{c}\text { Somewhat } \\
\text { Agree }\end{array}$ & $\begin{array}{c}\text { Strongly } \\
\text { Agree }\end{array}$ \\
\hline 1 & $\begin{array}{l}\text { I know what part(s) of } \\
\text { taking care of my diabetes } \\
\text { that I am dissatisfied } \\
\text { with. }\end{array}$ & $\begin{array}{l}\text { Strongly } \\
\text { Disagree }\end{array}$ & $\begin{array}{c}\text { Somewhat } \\
\text { Disagree }\end{array}$ & Neutral & $\begin{array}{c}\text { Somewhat } \\
\text { Agree }\end{array}$ & $\begin{array}{c}\text { Strongly } \\
\text { Agree }\end{array}$ \\
\hline 2 & $\begin{array}{l}\text { I am able to turn my } \\
\text { diabetes goals into a } \\
\text { workable plan. }\end{array}$ & $\begin{array}{l}\text { Strongly } \\
\text { Disagree }\end{array}$ & $\begin{array}{c}\text { Somewhat } \\
\text { Disagree }\end{array}$ & Neutral & $\begin{array}{c}\text { Somewhat } \\
\text { Agree }\end{array}$ & $\begin{array}{c}\text { Strongly } \\
\text { Agree }\end{array}$ \\
\hline 3 & $\begin{array}{l}\text { I can try out different } \\
\text { ways of overcoming } \\
\text { barriers to my diabetes } \\
\text { goals. }\end{array}$ & $\begin{array}{l}\text { Strongly } \\
\text { Disagree }\end{array}$ & $\begin{array}{c}\text { Somewhat } \\
\text { Disagree }\end{array}$ & Neutral & $\begin{array}{c}\text { Somewhat } \\
\text { Agree }\end{array}$ & $\begin{array}{c}\text { Strongly } \\
\text { Agree }\end{array}$ \\
\hline 4 & $\begin{array}{l}\text { I can find ways to feel } \\
\text { better about having } \\
\text { diabetes. }\end{array}$ & $\begin{array}{l}\text { Strongly } \\
\text { Disagree }\end{array}$ & $\begin{array}{l}\text { Somewhat } \\
\text { Disagree }\end{array}$ & Neutral & $\begin{array}{c}\text { Somewhat } \\
\text { Agree }\end{array}$ & $\begin{array}{c}\text { Strongly } \\
\text { Agree }\end{array}$ \\
\hline 5 & $\begin{array}{l}\text { I know the positive ways I } \\
\text { cope with diabetes-related } \\
\text { stress. }\end{array}$ & $\begin{array}{l}\text { Strongly } \\
\text { Disagree }\end{array}$ & $\begin{array}{c}\text { Somewhat } \\
\text { Disagree }\end{array}$ & Neutral & $\begin{array}{c}\text { Somewhat } \\
\text { Agree }\end{array}$ & $\begin{array}{c}\text { Strongly } \\
\text { Agree }\end{array}$ \\
\hline 6 & $\begin{array}{l}\text { I can ask for support for } \\
\text { having and caring for my } \\
\text { diabetes when I need it. }\end{array}$ & $\begin{array}{l}\text { Strongly } \\
\text { Disagree }\end{array}$ & $\begin{array}{l}\text { Somewhat } \\
\text { Disagree }\end{array}$ & Neutral & $\begin{array}{l}\text { Somewhat } \\
\text { Agree }\end{array}$ & $\begin{array}{c}\text { Strongly } \\
\text { Agree }\end{array}$ \\
\hline 7 & $\begin{array}{l}\text { I know what helps me stay } \\
\text { motivated to care for my } \\
\text { diabetes. }\end{array}$ & $\begin{array}{l}\text { Strongly } \\
\text { Disagree }\end{array}$ & $\begin{array}{c}\text { Somewhat } \\
\text { Disagree }\end{array}$ & Neutral & $\begin{array}{c}\text { Somewhat } \\
\text { Agree }\end{array}$ & $\begin{array}{c}\text { Strongly } \\
\text { Agree }\end{array}$ \\
\hline 8 & $\begin{array}{l}\text { I know enough about myself } \\
\text { as a person to make diabetes } \\
\text { care choices that are right for } \\
\text { me. }\end{array}$ & $\begin{array}{l}\text { Strongly } \\
\text { Disagree }\end{array}$ & $\begin{array}{c}\text { Somewhat } \\
\text { Disagree }\end{array}$ & Neutral & $\begin{array}{c}\text { Somewhat } \\
\text { Agree }\end{array}$ & $\begin{array}{c}\text { Strongly } \\
\text { Agree }\end{array}$ \\
\hline
\end{tabular}




\section{Appendix D}

\section{PAID}

Directions: Living with diabetes can sometimes be quite difficult. In day-to-day life, there may be numerous problems and hassles concerning diabetes and they can vary greatly in severity. Problems may range from minor hassles to major life difficulties. Listed below are a variety of potential problem areas which people with diabetes may experience. From your own view, consider the degree to which each of the listed items may currently be a problem for you and circle the appropriate number.

If an item does not apply to you (e.g. "Currently coping with complications", and you don't have any), please circle “ 0 ”.

Please note that we are asking you to indicate the degree to which each item may be bothering you in your life, NOT whether the item is merely true for you. For example, if you are "currently coping with complications", you would not necessarily rate this item with a high number. If you felt that this was not a bother or a problem for you, you would circle " 0 ". If this was very bothersome to you, you might circle " 5 ".

\begin{tabular}{|c|c|c|c|c|c|c|}
\hline \multirow{2}{*}{$\begin{array}{l}\text { To what degree are the following issues currently } \\
\text { problematic for you: } \\
\begin{array}{l}\text { 1. Not having clear and concrete goals for your diabetes } \\
\text { care? }\end{array} \\
\end{array}$} & \multicolumn{4}{|c|}{$\begin{array}{l}\text { Not a } \\
\text { problem }\end{array}$} & \multicolumn{2}{|c|}{$\begin{array}{l}\text { Serious } \\
\text { problem }\end{array}$} \\
\hline & 0 & 1 & 2 & 3 & 4 & 5 \\
\hline 2. Feeling discouraged with your diabetes regimen? & 0 & 1 & 2 & 3 & 4 & 5 \\
\hline $\begin{array}{l}\text { 3. Feeling scared when you think about having and living } \\
\text { with diabetes? }\end{array}$ & 0 & 1 & 2 & 3 & 4 & 5 \\
\hline $\begin{array}{l}\text { 4. Uncomfortable interactions around diabetes with family, } \\
\text { friends, acquaintances who do not have diabetes? (e.g. a } \\
\text { friend advising you on what to eat) }\end{array}$ & 0 & 1 & 2 & 3 & 4 & 5 \\
\hline 5. Feelings of deprivation regarding food and meals? & 0 & 1 & 2 & 3 & 4 & 5 \\
\hline $\begin{array}{l}\text { 6. Feeling depressed when you think about having and } \\
\text { living with diabetes? }\end{array}$ & 0 & 1 & 2 & 3 & 4 & 5 \\
\hline $\begin{array}{l}\text { 7. Not knowing if the mood or feelings you are } \\
\text { experiencing are related to your blood sugar levels? }\end{array}$ & 0 & 1 & 2 & 3 & 4 & 5 \\
\hline 8. Feeling overwhelmed by your diabetes regimen? & 0 & 1 & 2 & 3 & 4 & 5 \\
\hline 9. Worrying about low blood sugar reactions? & 0 & 1 & 2 & 3 & 4 & 5 \\
\hline $\begin{array}{l}\text { 10. Feeling angry when you think about having and living } \\
\text { with diabetes? }\end{array}$ & 0 & 1 & 2 & 3 & 4 & 5 \\
\hline 11. Feeling constantly concerned about food and eating? & 0 & 1 & 2 & 3 & 4 & 5 \\
\hline $\begin{array}{l}\text { 12. Worrying about the future and the possibility of serious } \\
\text { complications? }\end{array}$ & 0 & 1 & 2 & 3 & 4 & 5 \\
\hline $\begin{array}{l}\text { 13. Feelings of guilt or anxiety when you get off track with } \\
\text { your diabetes management? }\end{array}$ & 0 & 1 & 2 & 3 & 4 & 5 \\
\hline 14. Not "accepting" your diabetes? & 0 & 1 & 2 & 3 & 4 & 5 \\
\hline
\end{tabular}


HEALTH LITERACY 57

\begin{tabular}{|l|lllllrr|}
\hline $\begin{array}{l}\text { To what degree are the following issues currently } \\
\text { problematic for you: }\end{array}$ & $\begin{array}{l}\text { Not a } \\
\text { problem }\end{array}$ & & & $\begin{array}{r}\text { Serious } \\
\text { problem }\end{array}$ \\
\hline $\begin{array}{l}\text { 15. Feeling unsatisfied with your relationship with your } \\
\text { diabetes physician? }\end{array}$ & 0 & 1 & 2 & 3 & 4 & 5 \\
\hline $\begin{array}{l}\text { 16. Feeling that diabetes is taking up too much of your } \\
\text { mental and physical energy everyday? }\end{array}$ & 0 & 1 & 2 & 3 & 4 & 5 \\
\hline 17. Feeling alone with diabetes? & 0 & 1 & 2 & 3 & 4 & 5 \\
\hline $\begin{array}{l}\text { 18. Feeling that your friend and family are not supportive } \\
\text { of your diabetes management efforts? }\end{array}$ & 0 & 1 & 2 & 3 & 4 & 5 \\
\hline $\begin{array}{l}\text { 19. Coping with complications of diabetes? } \\
\text { 20. Feeling "burned out" by the constant effort to manage } \\
\text { diabetes? }\end{array}$ & 0 & 0 & 1 & 2 & 3 & 4 & 5 \\
\hline
\end{tabular}


Appendix E

NVS

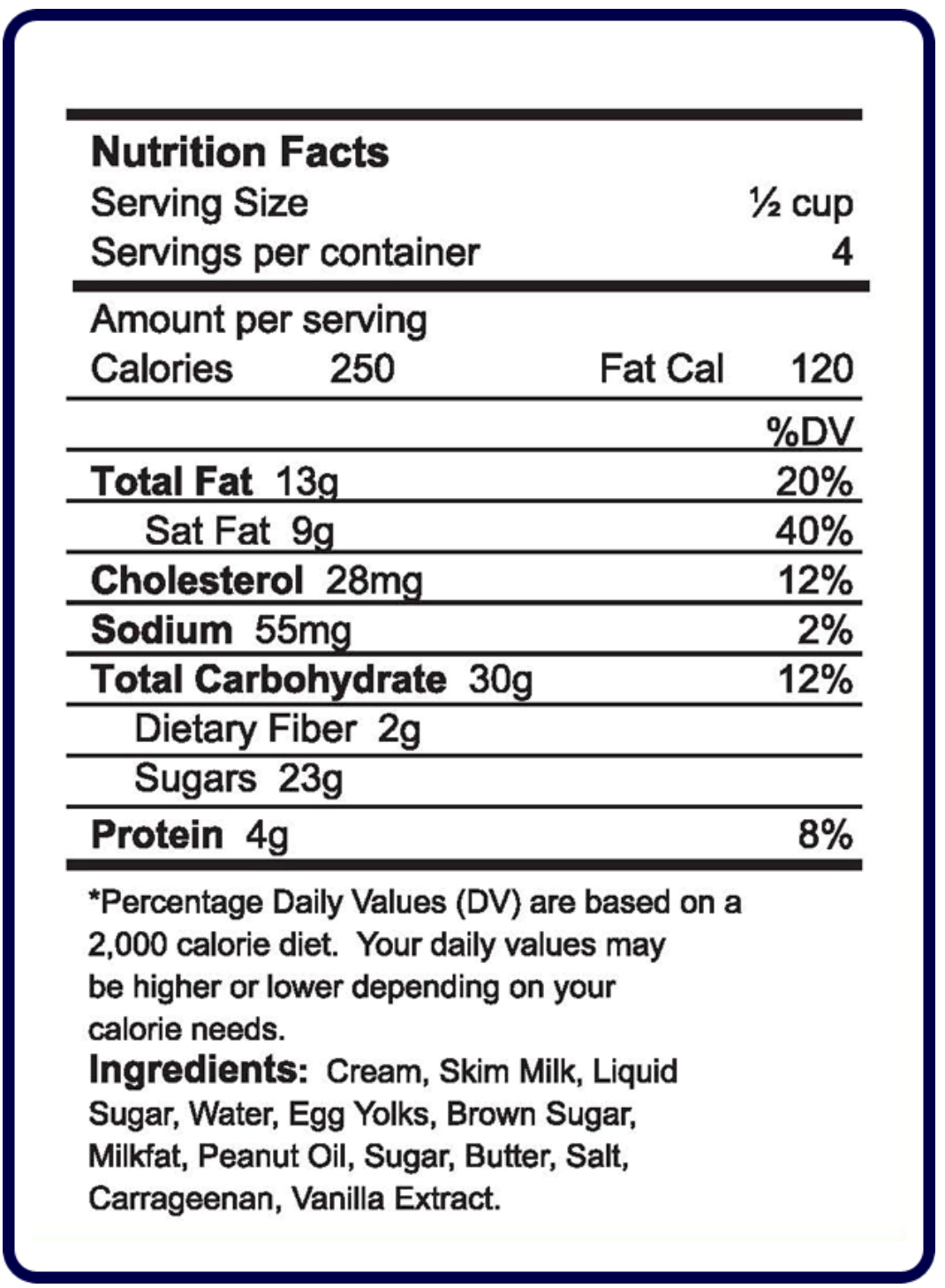

1. If you eat this entire container, how many calories will you eat?

2. If you are allowed to eat $60 \mathrm{~g}$ of carbohydrates as a snack, how much ice cream could you eat?

3. You are to reduce the amount of saturated fat in your diet. You usually have $42 \mathrm{~g}$ of saturated fat each day, which includes 1 serving of ice cream. If you stop eating the ice cream, how many grams of saturated fat would you be consuming each day?

4. If you usually eat 2500 calories per day, what percentage of your daily value of calories will you be eating if you eat one serving?

5. Pretend that you are allergic to the following substances: Penicillin, peanuts, latex gloves, and bee stings. Is it safe for you to eat this ice cream?

6. If no, why not? 


\section{Appendix F}

\section{DKT}

1. The diabetes diet is:

a. the way most American people eat

b. a healthy diet for most people

c. too high in carbohydrate for most people

d. too high in protein for most people

2. Which of the following is highest in carbohydrate?

a. Baked chicken

b. Swiss cheese

c. Baked potato

d. Peanut butter

3. Which of the following is highest in fat?

a. Low fat milk

b. Orange juice

c. Corn

d. Honey

4. Which of the following is a "free food"?

a. Any unsweetened food

b. Any dietetic food

c. Any food that says "sugar free" on the label

d. Any food that has less than 20 calories per serving
5. Glycosylated hemoglobin (hemoglobin A1) is a test that is a measure of your average blood glucose level for the past:

a. day

b. week

c. $6-10$ weeks

d. 6 months

6. Which is the best method for testing blood glucose?

a. Urine testing

b. Blood testing

c. Both are equally good

7. What effect does unsweetened fruit juice have on blood glucose?

a. Lowers it

b. Raises it

c. Has no effect

8. Which should not be used to treat low blood glucose?

a. 3 hard candies

b. 1/2 cup orange juice

c. 1 cup diet soft drink

d. 1 cup skim milk

9. For a person in good control, what effect does exercise have on blood glucose?
a. Lowers it
b. Raises it
c. Has no effect

10. Infection is likely to cause:

a. an increase in blood glucose

b. a decrease in blood glucose

c. no change in blood glucose

11. The best way to take care of your feet is to:

a. look at and wash them each day

b. massage them with alcohol each day c. soak them for one hour each day

d. buy shoes a size larger than usual

12. Eating foods lower in fat decreases your risk for:

a. nerve disease

b. kidney disease

c. heart disease

d. eye disease

13. Numbness and tingling may be symptoms of:

a. kidney disease

b. nerve disease

c. eye disease

d. liver disease

14. Which of the following is usually not associated with diabetes:
a. vision problems
b. kidney problems
c. nerve problems
d. lung problems 
15. Signs of ketoacidosis include:

a. shakiness

b. sweating

c. vomiting

d. low blood glucose

16. If you are sick with the flu, which of the following changes should you make?

a. Take less insulin

b. Drink less liquids

c. Eat more proteins

d. Test for glucose and ketones more often

17. If you have taken intermediate-acting insulin (NPH or Lente), you are most likely to have an insulin reaction in:

a. 1-3 hours

b. 6-12 hours

c. $12-15$ hours

d. more than 15 hours

18. You realize just before lunch time that you forgot to take your insulin before breakfast. What should you do now?

a. Skip lunch to lower your blood glucose

b. Take the insulin that you usually take at breakfast c. Take twice as much insulin as you usually take at breakfast

d. Check your blood glucose level to decide how much insulin to take
19. If you are beginning to have an insulin reaction, you should:
a. exercise
b. lie down and rest
c. drink some juice
d. take regular insulin

20. Low blood glucose may be caused by:

a. too much insulin

b. too little insulin

c. too much food

d. too little exercise

21. If you take your morning insulin but skip breakfast your blood glucose level will usually:

a. increase

b. decrease

c. remain the same

22. High blood glucose may be caused by:

a. not enough insulin

b. skipping meals

c. delaying your snack

d. large ketones in your urine

23. Which one of the following will most likely cause an insulin reaction?

a. heavy exercise

b. infection

c. overeating

d. not taking your insulin 


\section{Appendix G}

ECB Reasoning Questionnaire

In the chart below you will see two drugs listed "Drug 1" and "Drug 2." The third column tells you what will happen if you take these two medications at the same time. Use the chart below to answer the questions on the next page.

\begin{tabular}{|c|c|c|}
\hline Drug 1 & Drug 2 & Possible Side Effects \\
\hline $\begin{array}{c}\text { Lanoxin } \\
\text { (cardiac pill) }\end{array}$ & $\begin{array}{c}\text { Lasix } \\
\text { (water pill) } \\
\text { rash, vomiting, } \\
\text { headache, irregular } \\
\text { heartbeat, fever }\end{array}$ \\
\hline $\begin{array}{c}\text { Capoten } \\
\text { (blood pressure pill) }\end{array}$ & $\begin{array}{c}\text { Lasix } \\
\text { (water pill) }\end{array}$ & $\begin{array}{c}\text { rash, nausea, } \\
\text { irregular heartbeat }\end{array}$ \\
\hline $\begin{array}{c}\text { Capoten } \\
\text { (blood pressure pill) }\end{array}$ & $\begin{array}{c}\text { Genuine Bayer } \\
\text { Aspirin (pain reliever) }\end{array}$ & $\begin{array}{c}\text { chest pain, } \\
\text { vomiting, nausea, }\end{array}$ \\
\hline $\begin{array}{c}\text { Genuine Bayer } \\
\text { Aspirin } \\
\text { (pain reliever) }\end{array}$ & $\begin{array}{c}\text { Maalox } \\
\text { (antacid) }\end{array}$ & hever, confusion, \\
\end{tabular}

1) What kind of pill is Lasix?

2) Name two of the side effects listed for Aspirin and Maalox?

3) Name one of the medication names under the heading of Drug 1.

4) Mr. Albert takes two medications at 5 p.m. One of the medications was taken because of a severe headache. Twenty minutes later John begins to feel extremely nauseous. Which likely combination of drugs did John take?

5) One drug, taken in combination with several other medications, often causes an irregular heartbeat. Which drug might this be? 
6) When you take Bayer and Maalox, what possible side effect could you get that is different from any of the other symptoms listed in the chart?

7) If Mr. Albert is taking Capoten for high blood pressure should he take Aspirin at the same time? 
Below is a recent chart detailing the benefits offered by Medicare. Use the information below to answer the questions on the next page.

MEDICARE (PART A): HOSPITAL INSURANCE COVERED SERVICES FOR 1996

\begin{tabular}{|c|c|c|c|}
\hline Services & Benefit & Medicare Pays & You Pay \\
\hline $\begin{array}{l}\text { HOSPITALIZATION } \\
\text { Semiprivate room and } \\
\text { board, } \\
\text { general nursing and } \\
\text { other hospital } \\
\text { services and supplies }\end{array}$ & $\begin{array}{l}\text { First } 60 \text { days } \\
61 \text { st to } 90 \text { th day } \\
91 \text { st to } 150 \text { th day } \\
\text { beyond } 150 \text { days }\end{array}$ & $\begin{array}{l}\text { All but } \$ 736 \\
\text { All but } \$ 184 \text { a day } \\
\text { All but } \$ 368 \text { a day } \\
\text { Nothing }\end{array}$ & $\begin{array}{l}\$ 736 \\
\$ 184 \text { a day } \\
\$ 368 \text { a day } \\
\text { All costs }\end{array}$ \\
\hline $\begin{array}{l}\text { SKILLED NURSING } \\
\text { FACILITY CARE } \\
\text { Semiprivate room and } \\
\text { board, general nursing } \\
\text { and other hospital } \\
\text { services and } \\
\text { supplies.** }\end{array}$ & $\begin{array}{l}\text { First } 20 \text { days } \\
\text { Additional } 80 \text { days } \\
\text { Beyond } 100 \text { days }\end{array}$ & $\begin{array}{l}100 \% \text { of approved } \\
\text { amount } \\
\text { All but } \$ 92 \text { a day } \\
\text { Nothing }\end{array}$ & $\begin{array}{l}\text { Nothing } \\
\text { Up to } \$ 92 \text { a day } \\
\text { All costs }\end{array}$ \\
\hline $\begin{array}{l}\text { HOME HEALTH } \\
\text { CARE } \\
\text { Part-time or } \\
\text { intermittent skilled } \\
\text { care, home health aide } \\
\text { services, } \\
\text { durable medical } \\
\text { equipment and } \\
\text { supplies and other } \\
\text { services }\end{array}$ & $\begin{array}{l}\text { Unlimited as long as } \\
\text { you meet Medicare } \\
\text { requirements for } \\
\text { home health care } \\
\text { benefits. }\end{array}$ & $\begin{array}{l}80 \% \text { of approved } \\
\text { amount for } \\
\text { durable medical } \\
\text { equipment }\end{array}$ & $\begin{array}{l}\text { Nothing for services; } \\
20 \% \text { of approved } \\
\text { amount for durable } \\
\text { medical equipment. }\end{array}$ \\
\hline $\begin{array}{l}\text { HOSPICE CARE } \\
\text { Pain relief, symptom } \\
\text { management and } \\
\text { support services for the } \\
\text { terminally ill. }\end{array}$ & $\begin{array}{l}\text { For as long as doctor } \\
\text { certifies need. }\end{array}$ & $\begin{array}{l}\text { All but limited costs } \\
\text { for outpatient drugs } \\
\text { and inpatient respite } \\
\text { care. }\end{array}$ & $\begin{array}{l}\text { Limited cost sharing } \\
\text { for outpatient drugs } \\
\text { and inpatient respite } \\
\text { care. }\end{array}$ \\
\hline $\begin{array}{l}\text { BLOOD } \\
\text { When furnished by a } \\
\text { hospital or skilled } \\
\text { nursing facility during } \\
\text { a covered stay. }\end{array}$ & $\begin{array}{l}\text { Unlimited during a } \\
\text { benefit period if } \\
\text { medically necessary. }\end{array}$ & $\begin{array}{l}\text { All but first } 3 \text { pints } \\
\text { per calendar year. }\end{array}$ & For first 3 pints. ${ }^{* * *}$ \\
\hline
\end{tabular}

* 60 reserve days may be used only once

** Neither Medicare nor Medigap insurance will pay for most nursing home care

*** To the extent the three pints of blood are paid for or replaced under one part of Medicare during the calendar year, they do not have to be paid for or replaced under the other part. 
1) What is the name of the insurance described in the above chart?

2) Does this insurance cover hospitalization?

3) Does this insurance cover home health care aides?

4) If you had a very serious illness, so that you had to stay in the hospital for a long time, how much would you have to pay in starting on the 91st day?

5) If you are approved, how much do you have to pay for medical equipment such as a wheelchair or walker?

6) If you receive hospice care, what do you have to help pay for?

7) As you move into a sixth month in the hospital, how much of the costs do you have to pay? 
Mr. Cole is taking the three medications listed below. On Sunday night, he decides that he is going to put all his pills for the week into a pill box that is divided into chambers for morning, noon, evening, and bedtime, for every day of the week. Use the labels below it answer the following questions.

\section{DATE OF PRESCRIPTION: $\quad 05-31-97$}

DR: SNOW, J. R.

RX: 081221

John Cole

REFILLS 1

EXPIRES: 08-19-97

TAKE 1 CAPSULE ON MONDAY, WEDNESDAY, AND FRIDAY, AT

DATE OF PRESCRIPTION: 05-31-97

DR: SNOW， J. R. RX: 081222

John Cole

REFILLS 1

EXPIRES: $08-21-97$

DATE OF PRESCRIPTION: 05-31-97

DR: SNOW, J. R.

RX: 081223

John Cole

REFILLS 1

EXPIRES: 09-31-97 
1) Name the doctor who prescribed these three medications.

2) What is the patient's first name?

3) How many different medications is the patient taking?

4) How many pills should be in the Wednesday chamber?

5) How many pills will Mr. Cole take every night before he goes to bed?

6) What is the total number of pills Mr. Cole should take on Saturday?

7) By 2:00 p.m. on Tuesday, how many pills should Mr. Cole have taken for the day? 
Miss Braun wants a can of chili as part of her dinner. She goes to her cabinet and finds two different cans of chili. The labels for both cans are displayed below. Based on the information found in these labels answer the following questions.

CHILI BRAND A

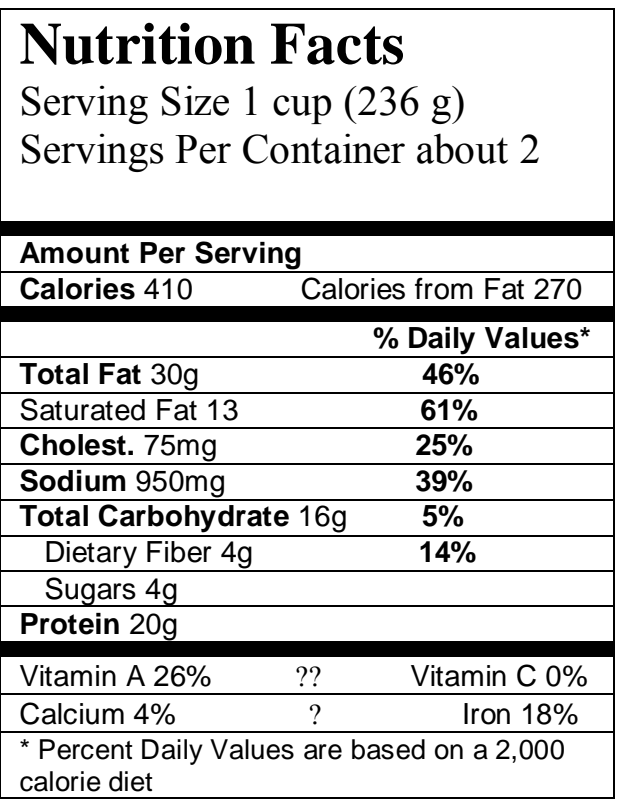

CHILI BRAND B

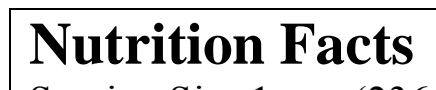

Serving Size 1 cup (236 g)

Servings Per Container about 2

\begin{tabular}{|c|c|c|}
\hline \multicolumn{3}{|c|}{ Amount Per Serving } \\
\hline Calories 190 & Calo & from Fat 25 \\
\hline \multicolumn{3}{|c|}{ \% Daily Values* } \\
\hline Total Fat $3 g$ & & $5 \%$ \\
\hline Saturated Fat 1g & & $5 \%$ \\
\hline Cholest. 75mg & & $25 \%$ \\
\hline Sodium $1250 \mathrm{mg}$ & & $39 \%$ \\
\hline Total Carbohydra & $17 g$ & $5 \%$ \\
\hline Dietary Fiber $3 g$ & & $12 \%$ \\
\hline \multicolumn{3}{|l|}{ Sugars $3 g$} \\
\hline \multicolumn{3}{|l|}{ Protein $19 \mathrm{~g}$} \\
\hline Vitamin A $25 \%$ & $? ?$ & Vitamin C 0\% \\
\hline Calcium 3\% & $?$ & Iron $15 \%$ \\
\hline \multicolumn{3}{|c|}{$\begin{array}{l}{ }^{*} \text { Percent Daily Values are based on a 2,000 } \\
\text { calorie diet }\end{array}$} \\
\hline
\end{tabular}

1) What product are these nutrition labels for?

2) What is the serving size in Brand A?

3) How many mg. of sodium is in Brand B?

4) Miss Braun needs to avoid foods that are high in fat, which can of chili would she be more likely to eat?

5) If she selects Brand $\mathbf{B}$, which categories will she get more of?

6) Which category does both cans of chili have the exact amount of?

7) If she wanted to cut down on her intake of salt, which can of chili would she want to avoid? 
Below you see what Mrs. Carver ate for the entire day in the first column. In the second column is a list of the number of servings Mrs. Carver had for each food group. Use this list and the food pyramid below to answer the following questions.

\section{BREAKFAST}

2 pancakes

$4 \mathrm{oz}$. orange juice

$1 / 2$ grapefruit

\section{LUNCH}

2 slices of cheese pizza

8 oz. of coke

\section{DINNER}

1 whole wheat roll

6 oz. broiled steak

1 cup of mixed greens

2 cups of salad

\section{SNACKS}

1 candy bar

1 apple

1 cup of popcorn

\section{SERVINGS}

1 bread and 1 fat

1 fruit

1 fruit

2 breads, 2 milks, $1 / 2$ veg. sweets

1 bread

2 protein

1 veg.

2 veg.

fats and sweets

1 fruit

1 bread

1) Name three of the foods on this food list from the bread and cereals food group.

2) Name one of the foods that was eaten as a snack.

3) Across the food groups, how many total servings did Mrs. Carver eat for dinner?

4) Looking at what Mrs. Carver ate for the entire day, what food group did she not eat enough of?

5) How many bread servings did Mrs. Carver eat for the entire day?

6) According to the food pyramid how many more fruits and meat servings does she need to eat today?

7) According to the food pyramid, which food group did she eat too much of today? 


\section{Appendix $\mathrm{H}$}

\section{ECB Knowledge Questionnaire}

1) Which of the following is highest in sodium?
a. bacon
b. mayonnaise
c. canned tomato juice
d. bagel

2) Which of the following is highest in fiber?
a. green peas
b. cheese
c. hot dog
d. white bread

3) The problem with cutting coated pills in half is that:
a. the medicine is in the coating
b. they may upset your stomach
c. you get more medication
d. this raises the price

4) Dosage is:
a. the amount of the drug you take each time
b. the time of the day you take the drug
c. the form the medication came in
d. the cost of the prescription

5) Current research indicates that eating foods lower in fat decreases your risk for:
a. high blood pressure
b. nerve disease
c. kidney disease
d. heart disease 
6) Which of the following is highest in total fat?
a. saltine cracker
b. corn
c. roast beef
d. honey

7) Which classification is not a major group in the food pyramid?
a. grain
b. meat
c. dairy
d. desserts

8) Beans is a member of which food group in the food pyramid?
a. dairy
b. grain
c. vegetable
d. meat

9) Don't take aspirin on an empty stomach because:
a. it will cause an upset stomach
b. it will make your head hurt
c. the aspirin won't enter your blood stream
d. it can be poisonous

10) When taking a bulk laxative like Metamucil:
a. drink lots of water
b. don't drink water to dilute drug
c. don't add artificial flavors
d. don't eat a big meal before or after

11) An expiration or "use by" date on a product means:
a. the last date the food should be used
b. last day the product can be expected to be at its peak quality
c. the date the food was processed or packaged
d. none of the above 
12) In order to retain as many vitamins as possible, when preparing vegetables, you should:
a. cook them thoroughly
b. cook them as little as possible
c. boil them
d. steam them till they are limp

13) When a drug expires:
a. you should use it up quickly
b. you should stop taking it
c. you should see your doctor
d. you should cut your pills in half to make them the prescription last longer

14) The "refills" listed on your prescription label means:
a. the number of refills of that drug you are allowed
b. the number of pills to take
c. the code for renewing your prescription
d. the time of day you take your medication

15) If you have a high cholesterol level, you have a greater chance of having a:
a. heart attack or stroke
b. cancer
c. diabetes
d. none of the above

16) The relationship between cholesterol and fat is:
a. foods high in cholesterol are high in fat
b. foods high in cholesterol are low in fat
c. the relationship varies with food
d. there is no relationship 
17) Which of the following is probably not a good room in which to store most medications?
a. bedroom
b. living room
c. bathroom
d. dining room

18) You should discontinue antibiotics when:
a. all finished
b. fever or other infectious symptoms go away
c. diarrhea results
d. you feel better

19) Digoxin is the most common heart medication. Before taking you should:
a. drink 8 oz. water
b. take pulse
c. take blood pressure
d. take a potassium supplement

20) After taking a drug, you feel dizzy. You should:
a. stop taking medication
b. call doctor in a few days
c. drink more water with pill
d. reduce dosage by half 
Appendix I

\section{SOME INFORMATION ABOUT YOU}

1. What is your current age?

2. Are you currently having problems with your diabetes?

$$
\square \text { Yes }
$$

$\square$ No

If yes, please specify:

3. When was your last HbA1c test for your blood glucose? (Month and Year)

4. What were the results of your last $\mathrm{HbA} 1 \mathrm{c}$ test?
口 $5.7 \%-6.4 \%$
- $6.5 \%-7.0 \%$
Greater than $7.0 \%$

5. When is your next HbA1c test? (Month and Year)

6. What is your marital status, are you:

$\square$ Married $\square$ Single, Never married?

$\square$ Widowed $\square$ Other (please specify below)

Divorced

7. Do you currently live:

Alone,

With a spouse, or

With Others? (please specify)

8. To which racial group do you belong?

$\square$ Caucasian/ White

African American or Black

American Indian or Alaska Native

Asian

Native Hawaiian or Other Pacific Islander

$\square$ Other (Please specify) 
9. Are you: $\square$ Male or $\square$ Female?

10. What is your current work status? Are you:

Employed full-time

Employed part-time $\square$ Retired, or $\square$ Unemployed/Homemaker?

$\square$ Other (please specify below)

11. What is the highest grade or level of education you have completed?

12. How much difficulty do you have paying your bills? Would you say:

$\square$ A great deal of difficulty

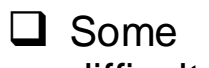

difficulty

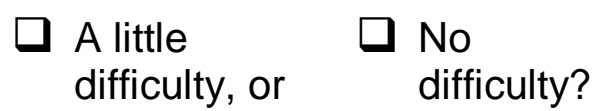

13. When were you diagnosed with Type 2 Diabetes?

14. In general, would you say your health is:

$\square$ Excellent $\square$ Very Good $\square$ Good $\square$ Fair $\square$ Poor

15. Compared to one year ago, how would you rate your health in general now?

$\begin{array}{lllll}\square \text { Much Better } & \text { Somewhat } & \text { Sobout the } & \text { Somewhat } & \square \text { Much worse } \\ \text { now than 1 } & \text { better now } & \text { same } & \text { worse now } & \text { now than 1 } \\ \text { year ago } & \text { than 1 year } & & \text { than 1 year } & \text { year ago } \\ & \text { ago } & & \text { ago } & \text { the same }\end{array}$

16. Height (feet and inches)

17. Weight (lbs)

18. Waist Measurement (inches)

19. Is your health now better, about the same, or not as good as it was 3 years ago?
Better
The Same
Not as Good

20. Do your health problems stand in the way of your doing the things you want to do?
$\square$ Not at all
A little
$\square$ A great deal

21. Compared with most other people your age, would you say your health is:

$\square$ Better $\square$ The Same $\square$ Not as Good 
22. Health Conditions: Please indicate which conditions you have \& indicate how much difficulty each causes you.

In terms of the difficulty it causes you, is it:

DO YOU HAVE:

\begin{tabular}{|c|c|c|c|c|c|c|c|}
\hline & & No & Yes & NONE & MILD & MODERATE & SEVERE \\
\hline a. & Arthritis & $\square$ & $\square$ & NONE & MILD & MODERATE & SEVERE \\
\hline b. & Heart trouble & $\square$ & $\square$ & NONE & MILD & MODERATE & SEVERE \\
\hline c. & Back problems & a & 口 & NONE & MILD & MODERATE & SEVERE \\
\hline d. & $\begin{array}{l}\text { Breathing } \\
\text { problems }\end{array}$ & $\square$ & $\square$ & NONE & MILD & MODERATE & SEVERE \\
\hline e. & Diabetes & $\square$ & $\square$ & NONE & MILD & MODERATE & SEVERE \\
\hline f. & $\begin{array}{l}\text { High blood } \\
\text { pressure }\end{array}$ & $\square$ & $\square$ & NONE & MILD & MODERATE & SEVERE \\
\hline g. & Cancer & $\square$ & $\square$ & NONE & MILD & MODERATE & SEVERE \\
\hline h. & $\begin{array}{l}\text { Other } \\
\text { (specify) }\end{array}$ & $\square$ & $\square$ & NONE & MILD & MODERATE & SEVERE \\
\hline i. & $\begin{array}{l}\text { Other } \\
\text { (specify) }\end{array}$ & $\square$ & $\square$ & NONE & MILD & MODERATE & SEVERE \\
\hline
\end{tabular}

23. Where do you use a computer?
At home
$\square$ At work
$\square$ At a library
At a senior center
At a friend or family member's home 
24. What do you use the internet for?

Sending and receiving e-mail or instant messages.

For work

Taking on-line classes.

Reading newspapers, magazines and/or books.

U Using an on-line social-networking site, such as Facebook, Twitter, Linkedin, or MySpace.

$\square$ Playing games online

Buying products online

Researching information about topics of interest.

Searching for jobs.

Making travel plans.

$\square$ Doing your banking online.

25. How often do you use the internet?

$\square$ Several times a day

$\square$ Daily

Every few days

$\square$ Less often than every few days 